\title{
Mechanical properties and microstructure of VPS and HVOF CoNiCrAlY coatings
}

\author{
S. Saeidi, K.T. Voisey, D.G. McCartney
}

Materials, Mechanics and Structures Research Division, Faculty of Engineering, The University of Nottingham, Nottingham, NG7 2RD, UK.

\begin{abstract}
HVOF and VPS coatings were sprayed using a Praxair (CO-210-24) CoNiCrAlY powder. Free standing coatings underwent vacuum annealing at different temperatures for times of up to $840 \mathrm{~h}$. Feedstock powder, as-sprayed and annealed coatings were characterised by SEM, EDS and XRD. The hardness and Young's modulus of as-sprayed and annealed HVOF and VPS coatings were measured, including determination of Young's moduli of the individual phases via nanoindentation and measurement of Young's moduli of coatings at temperatures up to $500^{\circ} \mathrm{C}$. The Eshelby inclusion model was used to investigate the effect of microstructure on the coatings' mechanical properties. The sensitivity of the mechanical properties to microstructural details was confirmed. Young's modulus was constant to $\sim 200^{\circ} \mathrm{C}$ then decreased with increasing measurement temperature. Annealing increased Young's modulus due to a combination of decreased porosity and $\beta$ volume fraction. Oxide stringers in the HVOF coating maintained its higher hardness than the VPS coating, even after annealing.
\end{abstract}




\section{1- Introduction}

MCrAlY (where $\mathrm{M}=\mathrm{Co}$, Ni or combination of both) type alloys which are used as both stand alone overlay coatings and thermal barrier coating (TBC) bond coats are amongst the most important protective coating materials applied to counteract hot corrosion and high temperature oxidation $[1,2,3,4]$. Like any other type of protective coating designed for oxidation resistance, MCrAlYs are capable of developing a thermodynamically stable slow growing oxide layer (thermally grown oxide, TGO). Ideally such an oxide layer is to be slow growing and resistant to scale failure. Scale failure may occur due to cracking and spallation, and depends strongly on oxide thickness, and further oxidation [2,5]. In fact, failure processes of TBCs are frequently associated with their decohesion from the TGO layer $[6,7]$.

Different processes, such as high velocity oxy-fuel (HVOF), plasma sprayings (APS, LPPS, VPS, AXPS), EBPVD and arc ion plating (AIP) [6], can be used to deposit MCrAlY overlay coatings. Important properties such as TGO growth rate and the composition of the bond coat are influenced by the fabrication process of the bond coat, the resultant microstructure and composition [8]. The use of different methods in depositing nominally the same coatings may also lead to very different results in terms of quality to cost ratio [9]. Investigating the microstructure of different thermally sprayed coatings and the stability of different phases at industrially relevant running temperatures is of great interest. Phase transformations in the MCrAlY bond coats can have a profound effect on the TBC life time [10],

High quality MCrAlY type coatings have been produced mostly by low pressure plasma spraying (LPPS) and vacuum plasma spraying (VPS) [4,5,8,9]. However, high costs 
associated with creating the required vacuum result in an overall high capital cost for coating production using these processes. HVOF spraying takes place at atmospheric pressure and is hence generally a lower cost process. In HVOF the high kinetic energy of the particles makes the flattening of the particles possible by deformation and leads to dense coatings with low oxygen content and high bond strength [1,11]. This allows oxidation sensitive materials to be sprayed in a plastic rather than molten state. Since the spraying takes place under atmospheric conditions, the possibility of oxidation of spraying particles during flight, and also of splats on the substrate prior to coverage by the next layer, still exists. However, this is somewhat abated by the lower temperature and higher velocity and hence lower transit time, hence oxidation significantly decreases due to the decreased level of melting. The effect of heat treatment and oxidation during spraying on the subsequent oxidation and oxidation rate of the MCrAlY coatings has been previously reported by the current authors [12].

It is known that the mechanical properties of the MCrAlY coatings significantly influence the initiation of the cracks in the superalloy substrate under thermo-mechanical fatigue conditions $[11,13]$. Due to microstructural features such as porosity, second phases, oxides, and weak bonding between splats $[14,15]$, the mechanical properties of the coatings may be different from those of the equivalent bulk material [16]. The mechanical properties of MCrAlY coatings are known to depend significantly on the spraying process and the microstructure [13]. Knowledge of elastic properties of sprayed coatings is necessary to predict the structural behaviour of a component in terms of strength and stiffness. These data are required to estimate residual stress and to predict damage and failure [16]. The lack of such data has limited modelling of the behaviour of the coating substrate systems $[17,18]$. Measurement of the elastic modulus of a coating is a difficult task due to the 
thinness of the coating which makes measurements highly sensitive to experimental errors, hence there are currently only limited published results on the high temperature Young's moduli of coatings of the type considered here $[16,19]$.

In this paper two different spraying techniques, VPS and HVOF, are used to form coatings from the same CoNiCrAlY feedstock powder. The equilibrium phases present at a range of temperatures, $800-1100^{\circ} \mathrm{C}$, are investigated. Hardness and Young's modulus, of both assprayed and annealed HVOF and VPS free-standing coatings are measured and compared. The Eshelby inclusion model $[20,21,22]$ is used to investigate the effect of coating porosity and $\beta$ volume fraction on Young's modulus.

It should be noted that no specific effort has been made to optimise coating deposition parameters, instead comparisons have been carried out between a typical VPS and a typical HVOF coating formed from the same feedstock powder.

\section{2- Experimental procedure}

A commercially gas atomised CoNiCrAlY powder (CO-210-24) supplied by Praxair was used in this work, the composition of which is given in Table 1. The nominal size range of the powder was specified as $-45+20 \mu \mathrm{m}$.

Mild steel was used as the substrate material with rectangular specimens of $60 \times 25 \times 1.8 \mathrm{~mm}$ for HVOF and slightly smaller $60 \times 20 \times 1.8 \mathrm{~mm}$ for VPS. The substrates were ground with 800 grade $\mathrm{SiC}$ paper in order to have a clean surface and enable coating detachment after spraying. For HVOF spraying, a commercial MetJet II (metallisation) gun was used. The HVOF system was operated with kerosene as fuel and nitrogen as the carrier gas. 
Compressed air jets were used to cool the samples during and after spraying. The substrates were mounted on a rotating sample holder while the spray gun traversed vertically. For the VPS spraying, a Plasma TECHNIK VPS system equipped with an F4 gun was used. The VPS chamber was first evacuated and back filled with Ar. Chamber pressure during spraying was 200 mbar. Waiting times of $20 \mathrm{~s}$ per pass were allowed between passes in order to minimise substrate heating. The spraying parameters employed for each spraying system are given in Table 2.

Following the spraying process, both HVOF and VPS coatings were detached from their substrates by bending the substrate [12,23]. Isothermal annealing of the free-standing coatings were carried out in vacuum at four different temperatures. The annealing times were increased with decreasing temperature in order to achieve equilibrium microstructures in all test samples: i.e. at $1100^{\circ} \mathrm{C}$ for $4 \mathrm{~h}, 1000^{\circ} \mathrm{C}$ for $24 \mathrm{~h}, 900^{\circ} \mathrm{C}$ for $90 \mathrm{~h}$ and $800^{\circ} \mathrm{C}$ for $840 \mathrm{~h}$. The annealing times were based on simple diffusion calculations of $\mathrm{Cr}$ in $\mathrm{Co}$, since chromium controls the kinetics. The specimens were subsequently quenched in water to preserve their high temperature microstructure. Scanning electron microscopy (SEM) equipped with energy dispersive spectroscopy (EDS), transmission electron microscopy (TEM), and X-ray diffraction (XRD) were used in order to analyse the as-sprayed and annealed samples, focusing on phase identification and phase composition. The measurements were conducted in areas away from the surface to avoid any surface oxides.

Young's modulus (E) and hardness of both as-sprayed and annealed samples were measured using a 3-point bending method and micro-hardness respectively. Young's modulus measurements were carried out at different temperatures, using a TA Q800 
Dynamic Mechanical Analyser (DMA). Coating strips of $20 \times 2 \mathrm{~mm}$ were cut from each assprayed and annealed $\left(900^{\circ} \mathrm{C}-1100^{\circ} \mathrm{C}\right)$ sample. Young's modulus measurements were carried out at temperatures in the range of $25^{\circ} \mathrm{C}$ to $500^{\circ} \mathrm{C}$. The hardness of the coatings was measured using a LECO M-400 micro-hardness tester with a $300 \mathrm{gf}$ load. Indentations were carried out on cross-sections with indents located in the middle of the coatings with a $20 \mu \mathrm{m}$ spacing between the indents. A Micro Materials nano-indenter with a standard diamond Berkovich indenter and a $5 \mathrm{mN}$ load in a $10 \times 10$ grid was used in order to measure the hardness and Young's modulus of the individual $\gamma$ and $\beta$ phases in the $1100^{\circ} \mathrm{C}$ annealed coatings. These samples were selected for nano-indentation since they had the largest sized beta phase regions. This increases the number of nano-indents that fall cleanly within a single phase, as opposed to in an interfacial region, and hence increases the proportion of nano-indents that can produce results that are valid for each single phase.

Image analysis was used in order to measure $\gamma$ and $\beta$ volume fractions as a function of annealing temperature. Furthermore, oxide plus porosity content of as-sprayed and annealed at $1100^{\circ} \mathrm{C} \mathrm{HVOF}$ and VPS coatings was measured using image analyses.

The Eshelby inclusion model $[20,21,22]$ was used in order to investigate the effect of $\beta$ volume fraction and porosity on the Young's modulus of different coatings. The key part of the model is that it removes the inclusion from the matrix, subjects the inclusion to a change in dimensions then determines the forces required to return the inclusion to its original dimensions. The deformed inclusion is then reinserted into the matrix, the forces on the inclusion are removed, and the resulting distortion of the surrounding matrix is determined. The strain corresponding to any given stress, and thereby the Young's modulus, can therefore be predicted [24]. This model uses ellipsoidal inclusions to 
represent included phases. Aspect ratios were defined so that values less than one corresponded to oblate spheroids and aspect ratios greater than one corresponded to prolate spheroids. The axes of all modelled inclusions were aligned perpendicularly to the coating substrate interface and axial Young's modulus results are reported. The model was run in two ways: (a) to study the effect of $\beta$ volume fraction the two phases considered were the $\gamma$ matrix with $\beta$ inclusions, the Young's modulus results obtained for the individual phases by nanoindentation were used; (b) investigation of porosity assumed a $29 \% \beta$ volume fraction dual phase material as the matrix, and used the predicted Young's modulus from (a) for this, with porosity represented as inclusions. Input data used for this modelling is given in Table 3.

\section{3- Results}

\section{3-1- Powder characteristics}

Spherical powder particles with a fine dendritic structure, were observed for the asreceived CoNiCrAlY powder by SEM (Figure 1). The XRD pattern of the powder (Figure 2) shows peaks associated with the $\gamma$-(fcc structure, lattice parameter close to $0.358 \mathrm{~nm}$ ) and $\beta-(\mathrm{Co}, \mathrm{Ni}) \mathrm{Al}$ (ordered $\mathrm{B} 2$, bcc, structure lattice parameter close to $0.286 \mathrm{~nm}$ ) [3,25] phases. A two phase microstructure was observed in back scattered electron SEM images (Figure 3). EDS analysis revealed the darker phase to be the $\beta-(\mathrm{Co}, \mathrm{Ni}) \mathrm{Al}$ intermetallic and the brighter phase to be the $\gamma$, solid solution phase.

\section{3-2-Microstructure of the as-sprayed coatings}

XRD spectra (Figure 4) of each as-sprayed coating revealed that while the VPS coating had a single $\gamma$ phase, the HVOF coating contained a $\beta-(\mathrm{Co}, \mathrm{Ni}) \mathrm{Al}$ phase in addition to the $\gamma$ phase. The different spraying methods used resulted in significant variations in the coating 
microstructure (Figure 5). HVOF sprayed coatings show higher amounts of incompletely melted particles compared to the VPS microstructure which consists of well-flattened particles indicating that most of the powder particles were melted before deposition. The HVOF coating is seen to have retained the two phase microstructure of the feedstock powder, while VPS coatings have a single phase $(\gamma)$ microstructure (Figure $5 \mathrm{c} \& d$ ). This observation is consistent with the XRD results.

\section{3-3-Microstructure of the annealed coatings}

Annealing reduced the porosity level of both coatings (Figure $5 \&$ Figure 6), this occurred to a greater extent for the VPS coating compared to the HVOF coating. This is consistent with the total porosity plus oxide contents of HVOF and VPS as-sprayed and annealed at $1100{ }^{\circ} \mathrm{C}$ coatings presented in Table 4.

Following annealing at $800^{\circ} \mathrm{C}$, the $\beta-(\mathrm{Co}, \mathrm{Ni}) \mathrm{Al}$ phase formed in the VPS coating and coarsened in the HVOF coating (Figure 7). In terms of phases, the microstructure of the HVOF coating did not seem to differ substantially from that observed in the as-sprayed coating, largely remaining a $\gamma$ matrix and $\mathrm{Al}$ rich $\beta$ precipitates. The only difference was the presence of areas that were larger in size and which had a slightly higher contrast than the $\beta$ precipitates that could be observed in both coatings after annealing. EDS analysis of these areas revealed very high $\mathrm{Cr}$ contents. Element mapping (Figure 8) confirmed the presence of a $\mathrm{Cr}$ rich phase. However, this phase was not seen in high quantities $(<2 \%)$ and was not distributed evenly throughout the coating. No XRD peaks were correlated with this additional phase (Figure 9). The specimens annealed at $900^{\circ} \mathrm{C}$ and $1000^{\circ} \mathrm{C}$ (Figure 10) showed no substantial microstructural differences compared to the samples annealed at 
$800^{\circ} \mathrm{C}: \gamma, \beta-(\mathrm{Co}, \mathrm{Ni}) \mathrm{Al}$ and the $\mathrm{Cr}$ rich phase were present in both $\mathrm{HVOF}$ and VPS coatings annealed at $900^{\circ} \mathrm{C}$ and $1000^{\circ} \mathrm{C} . \alpha-\mathrm{Cr}$ and $\sigma(\mathrm{Co}, \mathrm{Cr})$ were the candidate phases for the $\mathrm{Cr}$ rich phase. STEM analysis of the HVOF coating annealed at $900^{\circ} \mathrm{C}$ also confirmed the presence of the $\mathrm{Cr}$ rich phase. TEM analysis (Table 5) determined that the amount of $\mathrm{Cr}$ present in the $\mathrm{Cr}$ rich phase was much higher than Co, this phase was therefore attributed to be $\alpha-\mathrm{Cr}$.

SEM images of the microstructure of the coatings annealed at $1100^{\circ} \mathrm{C}$ for $4 \mathrm{~h}$ showed that at this temperature the only phases present were $\gamma$ and $\beta$ (Figure 11). $\alpha$-Cr was not seen in either coating (Figure $9 \&$ Figure 11).

For both coatings the $\beta$ volume fraction decreases with increasing annealing temperature, with the volume fraction present in the HVOF coating being consistently lower than that seen in the VPS coating (Figure 12).

\section{3-4- Mechanical properties}

\section{3-4-1- Hardness}

Figure 13 shows the hardness values for both HVOF and VPS coatings as a function of annealing temperature. Other data from the literature for similar materials is presented in Table 6 for comparison $[5,11,17]$.

The as-sprayed HVOF coating had a slightly higher hardness than the VPS coating. Both results were seen to be close to, though slightly higher than, previously published results for similar coatings. Annealing of both coatings produced a significant decrease in 
hardness. For all measurements the HVOF coatings consistently had higher hardnesses than the VPS coatings. Increase in annealing temperature to $1000^{\circ} \mathrm{C}$ produced a slight further decrease in hardness, which was followed by a slight increase for the $1100^{\circ} \mathrm{C}$ samples. This behaviour was seen for both types of coating.

\section{3-4-2- Young's modulus}

Young's modulus for the annealed HVOF and VPS samples as a function of measuring temperature as well as the results for the individual $\gamma$ and $\beta$ phases, as determined by nanoindentation of the $1100^{\circ} \mathrm{C}$ annealed coatings, are shown in Figure 14. Previously reported modulus results for various other relevant materials, including two MCrAlY alloys, taken from the literature are also plotted for comparison. Of these, the Co30Ni22 Cr9AlY is closest to the composition of the coatings studied in this work. It is seen that the experimental results for the Young's moduli of the sprayed coatings are similar to, though generally lower than those of bulk materials of similar composition. For all samples, after an initial plateau, the modulus decreased with increasing measurement temperature. The same overall trend was present in the data from the literature, however the initial plateau was absent. A clear increase in modulus with increasing annealing temperature was seen.

The nanoindentation results for each individual phase were greater than all results from the coatings, though some results from the coatings approached those measured for the $\beta$ phase. For both the VPS and HVOF coatings the Young's modulus of the $\gamma$ phase was significantly greater than that of the $\beta$ phase (Table 7). 


\section{3-4-3- Eshelby model}

Figure 15 shows that with increasing coating $\beta$ volume fraction the Young's modulus was predicted to decrease. This trend was also seen in the experimental results (Figure 15). However there was some discrepancy between the absolute values, with the predicted results being consistently clearly greater than the experimental results. The aspect ratio of the $\beta$ inclusions had a negligible effect on the predicted results. It should be noted that for completeness, aspect ratios from 0.01 to 100 were considered, whereas the observed values fall comfortably into the range of 0.1 to 10 (Figure $10 \&$ Figure 11).

Figure 16 illustrates the predicted effects of porosity level and aspect ratio on the Young's modulus of the coatings. Aspect ratios of between 0.1 and 10 are relevant to the coatings considered here and have therefore been highlighted. As the porosity level increased the modulus decreased. Low aspect ratio porosity (oblate spheroids with their axes perpendicular to the coating/substrate interface) was predicted to have a greater impact than high aspect ratio porosity (prolate spheroids with their axes perpendicular to the coating/substrate interface). Increasing porosity aspect ratio above 10 had very little further effect. The experimental results showed the same trends as the predictions. However, the absolute values of the experimental results were again lower than was predicted.

\section{4- Discussion}

The dendritic structure observed for the spherical MCrAlY powder particles (Figure 1) was due to the rapid solidification typical of the gas atomisation process used to produce the 
powder. The fine $\gamma+\beta$ microstructure of the powder (Figure 3) also resulted from this rapid solidification.

The as-sprayed HVOF had a two phase, $\gamma+\beta$, microstructure whereas the as-sprayed VPS coating essentially had a single phase $\gamma$ structure. Shibata et al. [8] have also reported similar microstructures for HVOF and LPPS CoNiCrAlY coatings. The difference in the microstructure of HVOF and VPS was due to the different temperatures experienced by the powder in each spraying process. Powder particles were exposed to a flame temperature of 2700-3200K for a relatively short time in the HVOF process. This resulted in only partial melting of the feedstock powder, and thus the original dual phase $\gamma+\beta$ microstructure of the feedstock powder was retained. In VPS coatings, the high temperature of the plasma flame $(>10000 \mathrm{~K})$ [5] and lower particle velocity resulted in more extensive melting of the powder particles. Rapid solidification on impact did not allow enough time for the $\beta$ $(\mathrm{Co}, \mathrm{Ni}) \mathrm{Al}$ phase to precipitate out and thus a single $\gamma$ phase was observed.

Annealing resulted in a reduction of porosity levels in both VPS and HVOF coatings. This reduction is due to diffusion which heals porosity via a sintering effect. Annealing had a greater effect in reducing the porosity level for the VPS coating compared to HVOF. VPS coatings are essentially oxide free [26], due to the process being carried out under vacuum. In HVOF coatings on the other hand, a thin oxide layer is generated around each particle during spraying, forming the oxide stringers seen in coating cross-sections (Figure 10). It is suggested that these oxide stringers acted as obstacles to diffusion, inhibiting the healing process in the HVOF coating. A similar effect and explanation has been previously reported [27]. 
After annealing at $800^{\circ} \mathrm{C}$ both $\mathrm{HVOF}$ and VPS coating had a $\gamma+\beta$ microstructure. However, a third phase was also visible. EDS analysis of this phase revealed a very high quantity of Cr. Since this phase was not present in large quantities it was not detected by XRD, so could not be directly identified. Toscano et al. [28] have reported the coexistence of the $\gamma$ phase with the $\sigma-(\mathrm{Co}, \mathrm{Cr})$ phase in samples of a similar CoNiCrAlY coating that had been annealed at $800^{\circ} \mathrm{C}$ for $300 \mathrm{~h}$. However, since the Co to $\mathrm{Cr}$ ratio in the $\mathrm{Cr}$-rich phase was very low it was assumed that it was $\alpha-\mathrm{Cr}$ rather than the $\sigma-(\mathrm{Co}, \mathrm{Cr})$ which would have had a higher Co to $\mathrm{Cr}$ ratio. Toscano et al. carried out their annealing process on an attached coating so interdiffusion between substrate and coating may have changed the coating composition $[25,29,30]$. Also their annealing process was carried out in air which will cause some oxidation of the coating and hence loss of elements such as $\mathrm{Al}, \mathrm{Cr}$, etc. According to Achar et al. [30] even a minor modification in composition of the MCrAlY coating will have a substantial affect on the phase equilibria.

The microstructure of HVOF and VPS coatings annealed at 900 and $1000^{\circ} \mathrm{C}$ was similar to that annealed at $800^{\circ} \mathrm{C}: \gamma, \beta-(\mathrm{Ni}, \mathrm{Co}) \mathrm{Al}$, and $\alpha-\mathrm{Cr}$ phases were present. The microstructure of the HVOF and VPS coatings annealed at $1100^{\circ} \mathrm{C}$ showed only the presence of the $\gamma+\beta$ phases, consistent with work by Shibata et al. [8]. Due to the low contrast between the $\alpha$ Cr phase and the $\beta$ phase, and also because of the scarcity of the $\alpha-\mathrm{Cr}$ phase, it was not possible to find a relationship between the annealing temperature and the quantity of the $\alpha$ Cr phase. No $\alpha-\mathrm{Cr}$ phase was observed for the $1100^{\circ} \mathrm{C}$ annealed samples, indicating that the stability limit of the $\alpha$-Cr phase is at a temperature between $1000^{\circ} \mathrm{C}$ and $1100^{\circ} \mathrm{C}$. The absence of $\gamma^{\prime}$ in the annealed coatings at all temperatures agrees with the findings of other authors $[8,28,30,31]$ who reported that Co tends to reduce the fraction of $\gamma^{\prime}$ and increase that of $\gamma$. 
Hardness values determined for both coatings indicated a higher hardness for HVOF compared to VPS. Different hardness values have been reported in the literature. Since hardness has a great dependence on the microstructure of the coating, even a slight change in for example porosity level or oxidation during spraying may have a big effect on the final hardness values. Zhang et al. [1], have reported a higher hardness value for VPS compared to HVOF. They have also observed a decrease in hardness in their heat treated coatings. Conversely, Higuera et al. [5] and Scrivani et al. [9] have reported higher hardness values for HVOF compared to VPS.

The annealing process clearly reduced the hardness compared to the as-sprayed values. The overall reduction in hardness resulting from annealing is largely attributed to stress relief of the coating. The hardness values did not significantly change as a function of annealing temperature. A slight decrease in hardness with increasing annealing temperature between $800^{\circ} \mathrm{C}$ and $1000^{\circ} \mathrm{C}$, followed by an increase for the $1100^{\circ} \mathrm{C}$ result was seen for both coatings. The fall in hardness following annealing is attributed to the coarsening of the $\beta$ phase and the resultant decrease in the effectiveness of the $\beta$ phase as an obstacle to dislocation motion. Hardness is known to be related to the temperature and the speed of the particles when they impact on substrate [5]. The higher speed of the HVOF projected particles can explain the coating's higher hardness due to work hardening. However, this explanation is only valid for the as-sprayed coatings since annealing is expected to eliminate this effect. It is possible that consistently higher hardness values are seen for HVOF compared to VPS coatings due to the presence of oxide stringers within the HVOF coating. The oxide stringers would act as obstacles to dislocation motion, hardening the HVOF coating compared to the oxide free VPS coating. 
The experimentally determined Young's moduli are less than those of bulk materials of similar compositions (Figure 14). This difference is attributed to porosity and weak intersplat bonding in the sprayed coatings [14], both features will tend to increase the strain tolerance of the coating. This is also consistent with the predictions of the Eshelby model. An intial plateau is seen in the experimental results for all coating samples. In each case the plateau ends at approximately $200^{\circ} \mathrm{C}$ and thereafter the Young's modulus of the coatings decreases, behaving in the same way as the reported bulk materials. The absence of this feature from literature values for the bulk form of similar materials (Figure 14) indicates that the plateau is due to some aspect of the sprayed microstructure, further investigation is required to determine a full explanation.

The observed changes in modulus due to annealing were thought to be due to two effects that had been observed to occur: (i) changes in $\beta$ volume fraction, (ii) decrease in porosity levels. The Eshelby inclusion model was used in order to investigate the relative magnitudes of these effects.

Results from the Eshelby inclusion model showed that a relatively large change in $\beta$ volume fraction from $29 \% \beta$ to $39 \% \beta$ resulted in a small change in the modulus, $\Delta \mathrm{E}=$ 6GPa. A similar change in modulus resulted from a change in porosity from $6 \%$ to $4 \%$. This suggests that the modulus is more sensitive to porosity level than it is to $\beta$ volume fraction. The main cause of the observed change in modulus is therefore attributed to the decrease in porosity caused by annealing. The progressive increase in modulus with increasing annealing temperature is attributed to the increasing $\beta$ volume fraction, since the porosity levels do not appear to change significantly with annealing temperature. 
The trend of the experimentally obtained results was in agreement with the results predicted by the Eshelby inclusion model. The absolute values of the experimental results were the same order of magnitude as the predicted results, but were approximately $30 \%$ lower. This variation is not surprising given the large number of microstructural features such as pores, splat boundaries, micro-cracks and unmelted particles which can influence the mechanical properties of coatings [14]. Of these factors only the porosity and $\beta$ volume fraction have been considered in this work. This variation between modelled and experimental results is similar to that previously reported by various authors. Azarmi et al. [14] reported modelled modulus values for coatings that were greater than experimental results. This was attributed to the failure of the model to account for the effect of additional microstructural characteristics, such as weak bonding across splat boundaries [14]. Kuroda et al. [32] ran the Eshelby inclusion model for APS Mo and reported that pore aspect ratios of between 0.1 and 0.01 were required for a satisfactory match between experimental and predicted values. They also comment that weak splat bonding could be a contributory factor. It is highly likely that diffusion during annealing strengthens initially weak intersplat bonds, thereby increasing the Young's modulus. Any such effect would be expected to be more pronounced at higher temperatures. The experimental results show an increase in Young's modulus with annealing temperature, suggesting that such an effect is occurring.

\section{5-Conclusions}

In addition to confirming the sensitivity of the mechanical properties of thermally sprayed coatings to microstructural details, the following conclusions can be drawn: 
- Nanoindentation has determined the Young's modulus of the individual $\gamma$ and $\beta$ phases.

- After an initial plateau that extends to $\sim 200^{\circ} \mathrm{C}$, the measured Young's modulus of CoNiCrAlY coatings decreases with increasing measurement temperature. This feature appears to result from the sprayed microstructure and warrants further investigation.

- Annealing increases the Young's modulus of CoNiCrAlY coatings. This variation is mainly due to a decrease in porosity due to annealing. The decrease in $\beta$ volume fraction with increasing annealing temperature also contributes to a further increase in the Young's modulus. It is also suggested that strengthening of inter-splat bonding via diffusion during annealing increases the Young's modulus.

- Oxide stringers in HVOF coatings result in an increased hardness compared to VPS coatings.

- Annealing of as-sprayed coatings produces a significant decrease in hardness, this is largely attributed to stress relief of the coatings.

- Variation in the $\beta$ volume fraction with annealing temperature causes only minor variations in hardness.

- $\alpha$-Cr may form during annealing of CoNiCrAlY coatings, the upper limit of stability of this phase is at a temperature between $1000^{\circ} \mathrm{C}$ and $1100^{\circ} \mathrm{C}$.

\section{Acknowledgements}

Thanks are due to Dr Nicola Everitt and Mike Davies, both of the Materials, Mechanics and Structures Research Division, Faculty of Engineering, The University of Nottingham, for carrying out the nanoindentation work. Thanks are also due to Prof T.W. Clyne and Mr 
K.A. Roberts of The University of Cambridge for carrying out plasma spraying and providing the relevant experimental details. 


\section{References}

[1]Zhang, D., S. J. Harris and D. G. McCartney: Mechanical Properties and Microstructure of HVOF Sprayed Co and Ni Alloy Coatings. Thermal spray 2003: Advancing the Science \& Applying the Technology(2003) 829-836.

[2]Zhao, L., M. Parco and E. Lugscheider: High velocity oxy-fuel thermal spraying of a NiCoCrAIY alloy. Surface and Coatings Technology(2004) 179, 272-278.

[3]Fritscher , K. and Y. Lee: Investigation of an as-sprayed NiCoCrAIY overlay coating microstructure and evolution of the coating. Materials and Corrosion(2005) 56, 5-14.

[4]Shibata, M., S. Kuroda, M. Watanabe and Y. Sakamoto: Oxidation property of CoNiCrAIY coatings prepared by various thermal spraying techniques. Materials Science Forum(2006) 522-523, 339-344.

[5]Higuera, V., F. J. Belzunce and J. Riba: Influence of the thermal-spray procedure on the properties of a CoNiCrAIY coating. Surface and Coatings Technology(2006) 200, 5550-5556.

[6]Pomeroy, M. J.: Coatings for gas turbine materials and long term stability issues. Materials \& Design(2005) 26, 223-231.

[7]Evans, H. E. and M. P. Taylor: Delamination processes in thermal barrier coating systems. Journal of Corrosion Science and Engineering(2003) 6.

[8]Shibata, M., S. Kuroda, H. Murakami, M. Ode, M. Watanabe and Y. Sakamoto (2005). Comparison of microstructure and oxidation behavior of CoNiCrAIY bond coatings prepared by different thermal spray processes. 1st Asian Thermal Spray Conference (ATSC 2005), Nagoya, JAPAN.

[9]Scrivani, A., U. Bardi, L. Carrafiello, A. Lavacchi, F. Niccolai and G. Rizzi: A comparative study of high velosity oxygen fuel, vacuum plasma, and axial plasma spray for the deposition of CoNiCrAIY bond coat alloy. Journal of Thermal Spray Technology(2003) 12, 504-507.

[10]Naumenko, D., V. Shemet, L. Singheiser and W. J. Quadakkers: Failure mechanisms of thermal barrier coatings on MCrAIY-type bondcoats associated with the formation of the thermally grown oxide. Journal of Materials Science(2009) 44, 1687-1703.

[11]Itoh, Y., M. Saitoh and Y. Ishiwata: Characteristics of MCrAlY Coatings Sprayed by High Velocity Oxygen-Fuel Spraying System. Journal of Engineering for Gas Turbines and Power(2000) 122,43 - 49.

[12]Saeidi, S., K. T. Voisey and D. G. McCartney: The effect of heat treatment on the oxidation behavior of HVOF and VPS CoNiCrAIY coatings. Journal of Thermal Spray Technology(2009) 182, 209-216.

[13]Waki, H., T. Kitamura and A. Kobayashi: Effect of Thermal Treatment on High-Temperature Mechanical Properties Enhancement in LPPS, HVOF, and APS CoNiCrAIY Coatings. Journal of Thermal Spray Technology(2009) 18, 500-509.

[14]Azarmi, F., T. Coyle and J. Mostaghimi: Young's modulus measurement and the study of the relationship between mechanical properties and microstructure of air plasma sprayed alloy 625 . Surface \& Coatings Technology(2008) doi:10.1016/j.surfcoat.2008.09.035.

[15]Li, C. J., A. Ohmori and R. McPherson: The relationship between microstructure and Young's modulus of thermally sprayed ceramic coatings. JOURNAL OF MATERIALS SCIENCE(1997) 32, 997-1004. 
[16]Beghini, M., G. Benamati, L. Bertini and F. Frendo: Measurement of coatings' elastic properties by mechanical methods: Part 2. Application to thermal barrier coatings. Experimental Mechanics(2001) 41, 305-311.

[17]Itoh, Y. and M. Saitoh: Mechanical Properties of Overaluminized MCrAlY Coatings at Room Temperature. Journal of Engineering for Gas Turbines and Power(2005) 127, 807-813.

[18]Rico, A., J. Gómez-García, C. J. Múnez, P. Poza and V. Utrilla: Mechanical properties of thermal barrier coatings after isothermal oxidation.: Depth sensing indentation analysis. Surface and Coatings Technology(2009) 203, 2307-2314.

[19]Beghini, M., L. Bertini and F. Frendo: Measurement of coatings' elastic properties by mechanical methods: Part 1. Consideration on experimental errors. Experimental Mechanics(2001) 41, 293-304.

[20]Clyne, T. W. and P. J. Withers (1993). An introduction to metal matrix composites. Cambridge, Cambridge University Press.

[21]Eshelby, J. D.: The determination of the elastic field of an ellipsoidal inclusion, and related problems. Proceeding of the royal society of london series A-Mathematical and Physical sciences(1957) 241, 376-396.

[22]Eshelby, J. D.: The elastic field outside an ellipsoidal inclusion. proceeding of the royal society of london series A-Mathematical and Physical sciences(1959) 252, 561-569.

[23]Thompson, J. A., Y. C. Tsui, R. C. Reed, D. S. Rickerby and T. W. Clyne: Creep of plasma sprayed CoNiCrAIY and NiCrAIY bond coats and its effects on residual stresses during thermal cycling of thermal barrier coating systems High Temperature Surface Engineering (2000) 6th International Conference on Engineering the Surface, 199-212

[24]D. Hull and T. W. Clyne (1996). An Introduction to Composite Materials, C.U.P.

[25]Poza, P. and P. S. Grant: Microstructure evolution of vacuum plasma sprayed CoNiCrAIY coatings after heat treatment and isothermal oxidation. Surface and Coatings Technology(2006) 201, 2887-2896.

[26]Toma, D., W. Brandl and U. Köster: Studies on the transient stage of oxidation of VPS and HVOF sprayed MCrAlY coatings. Surface and Coatings Technology(1999) 120-121, 8-15.

[27]Brandl, W., D. Toma, J. Kruger, H. J. Grabke and G. Matthaus: The oxidation behaviour of HVOF thermal-sprayed MCrAIY coatings. Surface and Coatings Technology(1997) 94-95, 21-26.

[28]Toscano, J., A. Gil, T. Huttel, E. Wessel, D. Naumenko, L. Singheiser and W. J. Quadakkers: Temperature dependence of phase relationships in different types of MCrAIY-coatings. Surface and Coatings Technology(2007) 202, 603-607.

[29]Krukovskya, P., K. Tadlyaa, A. Rybnikovb, I. Kryukovb, N. Mojaiskaiab, V. Kolarikc and M. Juez-Lorenzoc: Lifetime Modelling for MCrAIY Coatings in Industrial Gas Turbine Blades. Materials $\operatorname{research}(2002) \quad 7,43-47$.

[30]Achar, D. R. G., R. Munoz-Arroyo, L. Singheiser and W. J. Quadakkers: Modelling of phase distributions in MCrAIY coatings and their interactions with nickel based alloys. Journal of Physics IV, France(2004) 120, 231-238.

[31]Tamarin, Y. (2002). Protective coatings for turbine blades. Ohio, ASM International.

[32]Kuroda, S. and T. W. Clyne: The quenching stress in thermally sprayed coatings. Thin Solid Films(1991) 200, 49-66. 


\section{Figure captions}

Figure 1. Secondary electron SEM images of (a) CoNiCrAlY feedstock powder, (b) crosssection of powder revealing dendiritic structure.

Figure 2. XRD pattern of the CoNiCrAlY powder.

Figure 3. SEM micrograph showing the two phase microstructure of the feedstock powder.

Figure 4. XRD pattern of as-sprayed HVOF \& VPS coatings.

Figure 5. Back scattered electron SEM images of (a) VPS coating, (b) HVOF coating, (c) $\&$ (d) are higher magnifications of (a) \& (b) respectively.

Figure 6. Cross-sections of (a) VPS, and (b) HVOF, coatings annealed at $800^{\circ} \mathrm{C}$ for 840 hours.

Figure 7. Back scattered electron SEM images of cross-sections of specimens annealed at $800^{\circ} \mathrm{C}$ for 840 hours (a) VPS coating, (b) HVOF coating. $\gamma, \beta$ and a $\mathrm{Cr}$ rich phase are visible.

Figure 8. Chromium rich regions detected by EDS mapping in VPS coating annealed at $800^{\circ} \mathrm{C}$.

Figure 9. XRD patterns of (a) VPS and (b) HVOF coatings annealed at 800, 900, 1000, and $1100^{\circ} \mathrm{C}$.

Figure 10. SEM cross-sections of (a) VPS and (b) HVOF specimens annealed at $900^{\circ} \mathrm{C}$ and $1000^{\circ} \mathrm{C}$ for $90 \mathrm{~h}$ and $24 \mathrm{~h}$ respectively. 
Figure 11. SEM cross-sections of (a) VPS and (b) HVOF coatings annealed at $1100^{\circ} \mathrm{C}$ for 4h.

Figure 12. $\beta$ volume fraction as a function of annealing temperature for HVOF \& VPS coatings.

Figure 13. Vickers hardness values for HVOF and VPS coatings as a function of annealing temperature.

Figure 14. Young's modulus as a function of measuring temperature for (a) VPS assprayed \& annealed coatings, (b) HVOF as-sprayed \& annealed coatings and (c) literature values for different relevant alloys and $\gamma$-Ni \& $\beta$-NiAl single phases [31].

Figure 15. Effect of $\beta$ volume fraction on HVOF Young's modulus. The initial point is the modulus of the $\gamma$ phase measured by nano-indentation. Dotted lines indicate the region of interest. The individual data points are the modulus of HVOF coating measured using DMA.

Figure 16. Young's modulus as a function of aspect ratio \& porosity level for HVOF coating. Aspect ratios relevant to this work are 1-10 for porosity levels of less than $6 \%$. Aspect ratios greater than 1 correspond to porosity that is mainly parallel to the interface. The crosses $(x)$ in the graph are the experimentally measured values for annealed and as-sprayed HVOF samples. 


\section{Tables}

Table 1. Chemical composition of the powder, LCO210, (wt \%)

\begin{tabular}{ccccc}
\hline Co & Ni & Cr & Al & Y \\
\hline 38.5 & 32 & 21 & 8 & 0.5 \\
\hline
\end{tabular}


Table 2. Spraying parameters.

\begin{tabular}{lclc}
\hline \multicolumn{1}{c}{ HVOF } & \multicolumn{2}{c}{ VPS } \\
\hline Spray distance $(\mathrm{mm})$ & 356 & Spray distance $(\mathrm{mm})$ & 280 \\
Substrate cooling & air & Current (A) & 600 \\
Traverse speed (m/s) & 1 & Voltage $(\mathrm{V})$ & 63 \\
$\mathrm{~N}_{2}$ carrier gas flow rate $(1 / \mathrm{min})$ & 5.5 & Power $(\mathrm{kW})$ & 40 \\
$\mathrm{O}_{2}$ gas flow rate $(\mathrm{l} / \mathrm{min})$ & 890 & Ar flow $(1 / \mathrm{min})$ & 50 \\
Kerosene flow rate $(\mathrm{ml} / \mathrm{min})$ & 470 & $\mathrm{H}_{2}$ flow $(1 / \mathrm{min})$ & 10 \\
Nozzle length $(\mathrm{mm})$ & 100 & Traverse speed $(\mathrm{mm} / \mathrm{s})$ & 84 \\
\hline
\end{tabular}


Table 3. Input parameters for Eshelby inclusion model.

\begin{tabular}{ccccc}
\hline Input parameter & \multicolumn{4}{c}{ Phase } \\
\cline { 2 - 5 } & $\gamma$ matrix & $\gamma+\mathbf{2 9 \%} \boldsymbol{\beta}$ matrix & $\boldsymbol{\beta}$ inclusion & porosity inclusion \\
\hline $\begin{array}{c}\text { Young's modulus } \\
\text { (GPA) }\end{array}$ & 231 & 215 & 181 & 0 \\
\hline Poisson ratio & 0.3 & 0.3 & 0.3 & 0 \\
\hline
\end{tabular}


Table 4. Porosity plus oxide content for as-sprayed and annealed at $110{ }^{\circ} \mathrm{C}$ HVOF and VPS coatings.

Results obtained from image analysis.

\begin{tabular}{|c|c|c|c|c|}
\hline & \multicolumn{2}{|c|}{ As-sprayed } & \multicolumn{2}{|c|}{$\begin{array}{c}\text { Annealed at } \\
1100^{\circ} \mathrm{C}\end{array}$} \\
\hline & HVOF & VPS & HVOF & VPS \\
\hline Porosity + oxide $(\%)$ & 4 & 5.5 & 2 & $<1$ \\
\hline
\end{tabular}


Table 5. Composition of the $\alpha-\mathrm{Cr} \& \beta$ - $(\mathrm{Ni}, \mathrm{Co}) \mathrm{Al}$ phase in $\mathrm{HVOF}$ coating annealed at $900^{\circ} \mathrm{C}$ for $90 \mathrm{hr}$. Results from TEM analysis.

\begin{tabular}{c|cc}
\hline Elements & $\begin{array}{c}\alpha-C r \\
(w t \%)\end{array}$ & $\begin{array}{c}\beta \\
(w t \%)\end{array}$ \\
\hline $\mathrm{Al}$ & 2 & 29 \\
$\mathrm{Cr}$ & 86 & 8 \\
$\mathrm{Co}$ & 7 & 20 \\
$\mathrm{Ni}$ & 4 & 42 \\
\hline
\end{tabular}


Table 6. Vickers hardness data from the published literature for materials similar to those used in this work [5,11,17].

\begin{tabular}{c|ccc}
\hline Material & Hardness $($ HV $)$ & Comment & Microstructure \\
\hline Alloy 625 & $213 \pm 38$ & As-rolled & $\gamma$ \\
Alloy 625 & $118 \pm 43$ & Annealed & $\gamma$ \\
Alloy 718 & 349 & Bar & Not specified \\
Ni23Co17Cr12AlY & 500 & VPS sprayed & $\gamma+\beta$ \\
Ni22Co17Cr12AlY & 387 & VPS sprayed & $\gamma+\beta$ \\
& & then annealed & \\
Ni22Co17Cr12AlY & 438 & HVOF sprayed & $\gamma+\beta$ \\
Ni22Co17Cr12AlY & 475 & HVOF sprayed & $\gamma+\beta$ \\
& & then annealed & \\
Co32Ni21Cr9AlY & $155 \pm 18$ & Plasma sprayed & Not specified \\
Co32Ni21Cr9AlY & $418 \pm 31$ & HVOF sprayed & Not specified \\
Co32Ni21Cr8AlY & 450 & VPS sprayed & $\gamma+\beta$ \\
\hline
\end{tabular}


Table 7. Young's modulus results for individual phases as determined by nanoindentation.

\begin{tabular}{l|cc}
\hline & $\begin{array}{c}E_{\gamma} \\
(G P a)\end{array}$ & $\begin{array}{c}E_{\beta} \\
(G P a)\end{array}$ \\
\hline HVOF & $231 \pm 11$ & $181 \pm 6$ \\
VPS & $213 \pm 9$ & $182 \pm 5$ \\
& & \\
\hline
\end{tabular}




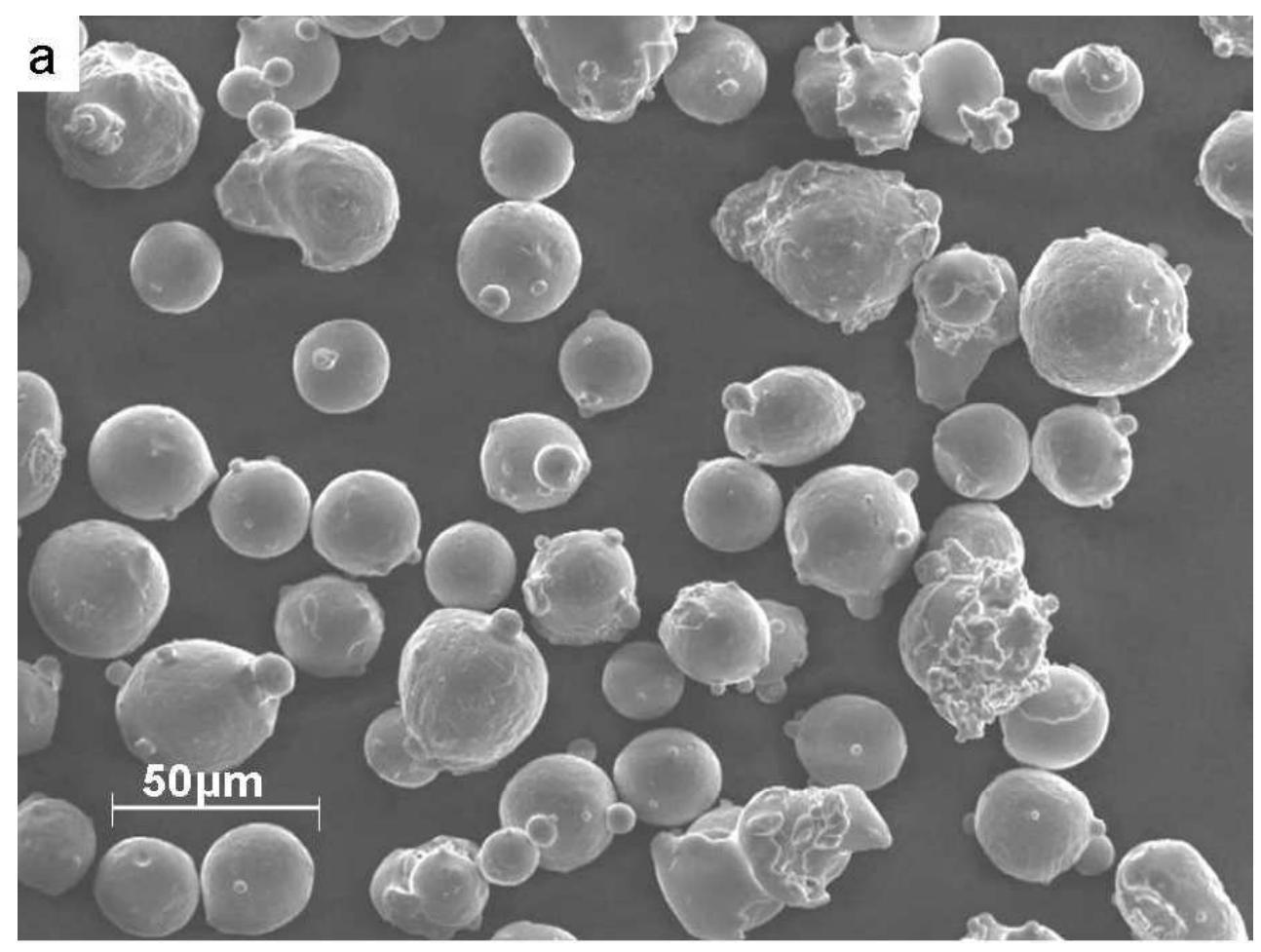

$76 \times 57 \mathrm{~mm}(300 \times 300$ DPI $)$ 


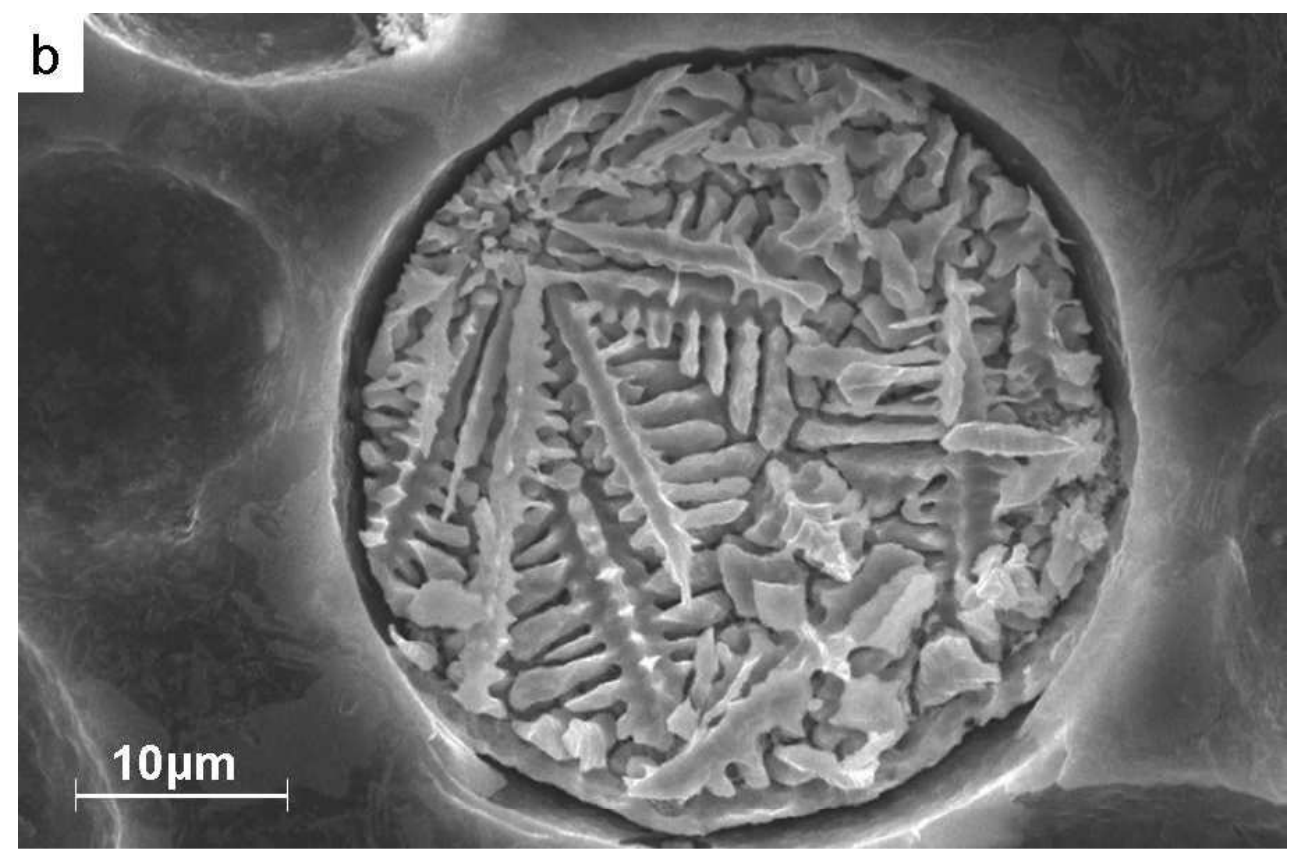

$77 \times 50 \mathrm{~mm}(300 \times 300 \mathrm{DPI})$ 


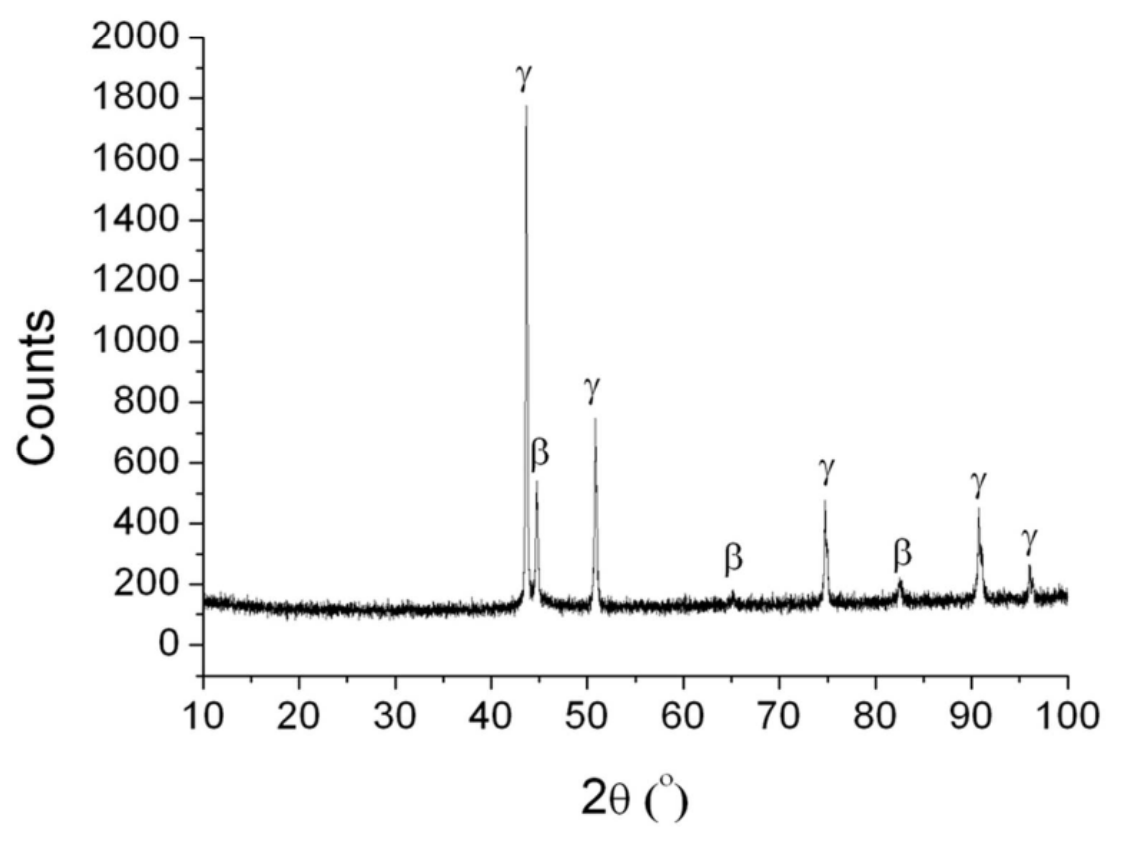

$74 \times 56 \mathrm{~mm}(600 \times 600 \mathrm{DPI})$ 


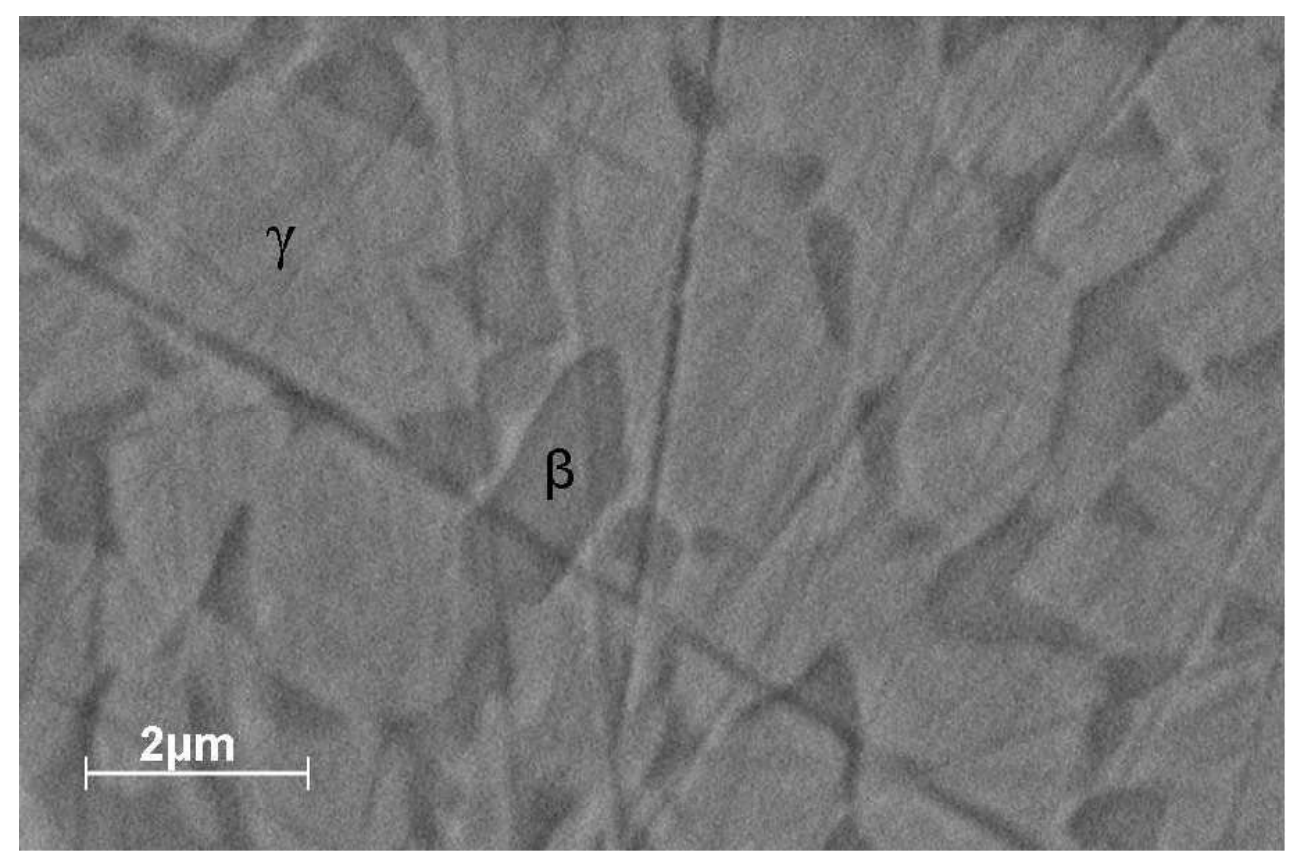

$77 \times 50 \mathrm{~mm}(300 \times 300$ DPI $)$ 


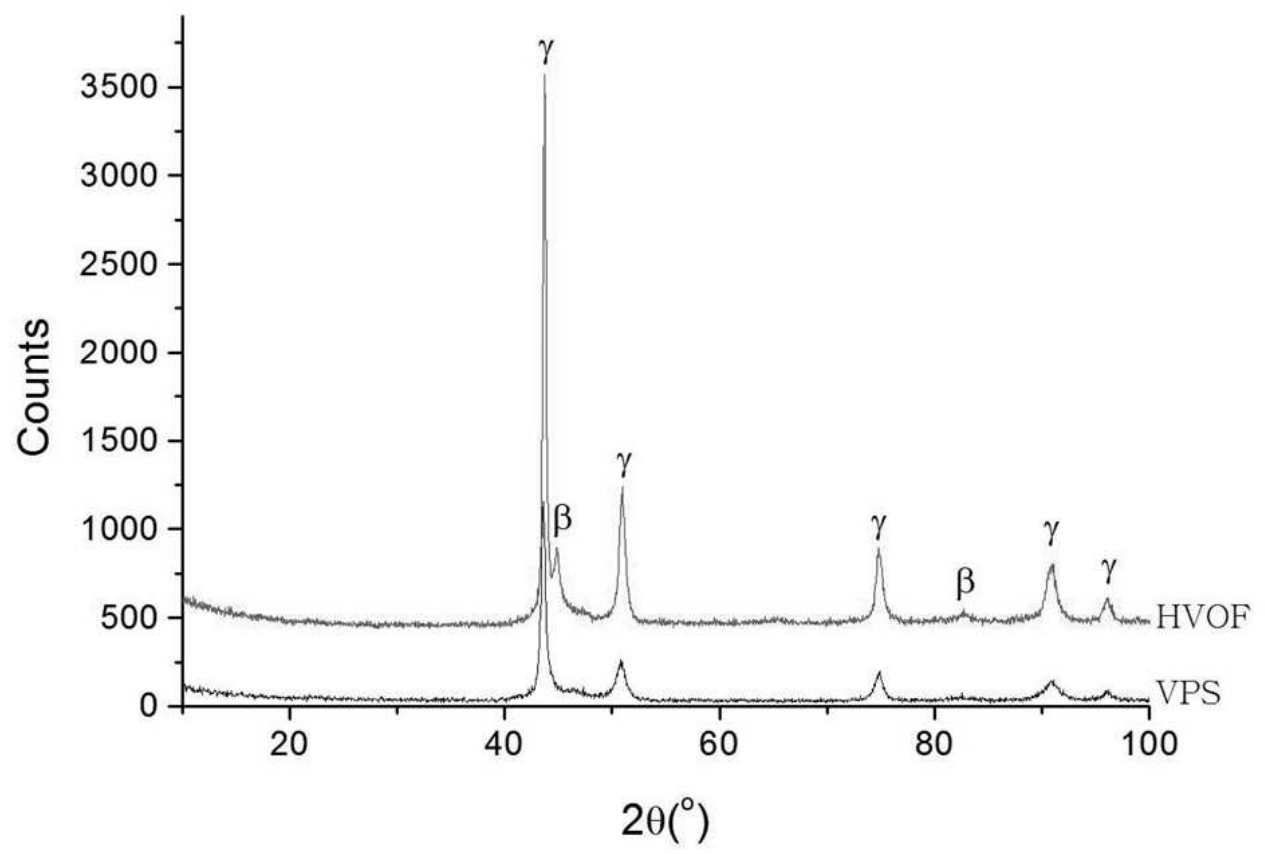

$80 \times 54 \mathrm{~mm}(300 \times 300 \mathrm{DPI})$ 


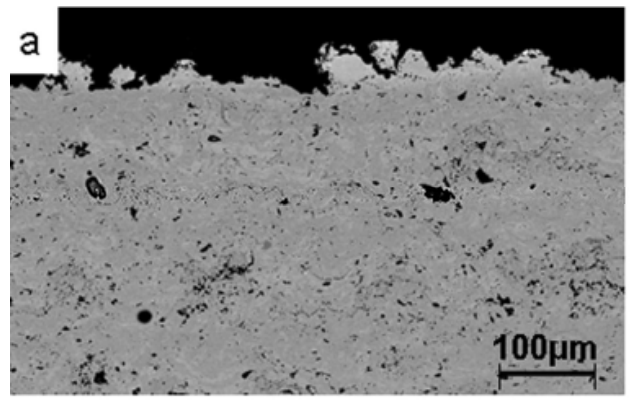

Unmelted powder

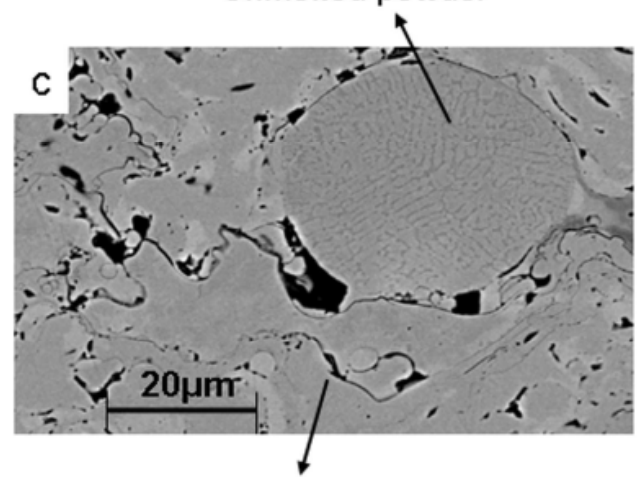

Single phase $(\gamma)$ resolidified material

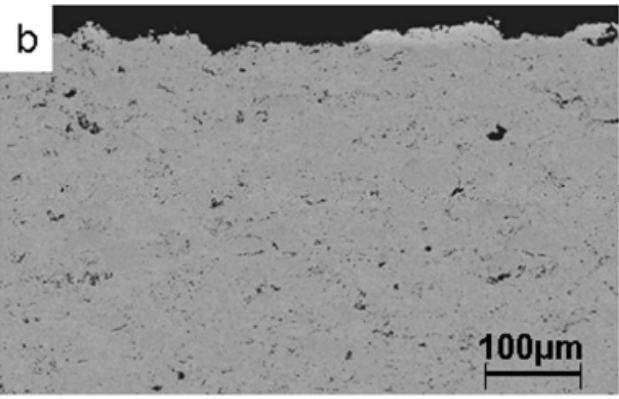

Incompletely melted powder particle

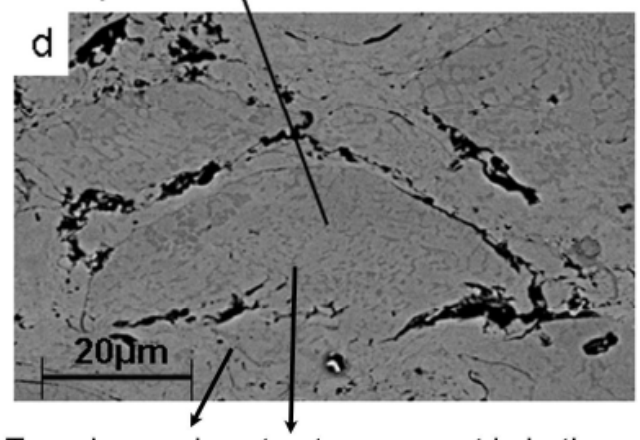

Two phase microstructure present in both resolidified and incompletely melted material

$196 \times 153 \mathrm{~mm}(300 \times 300$ DPI $)$ 

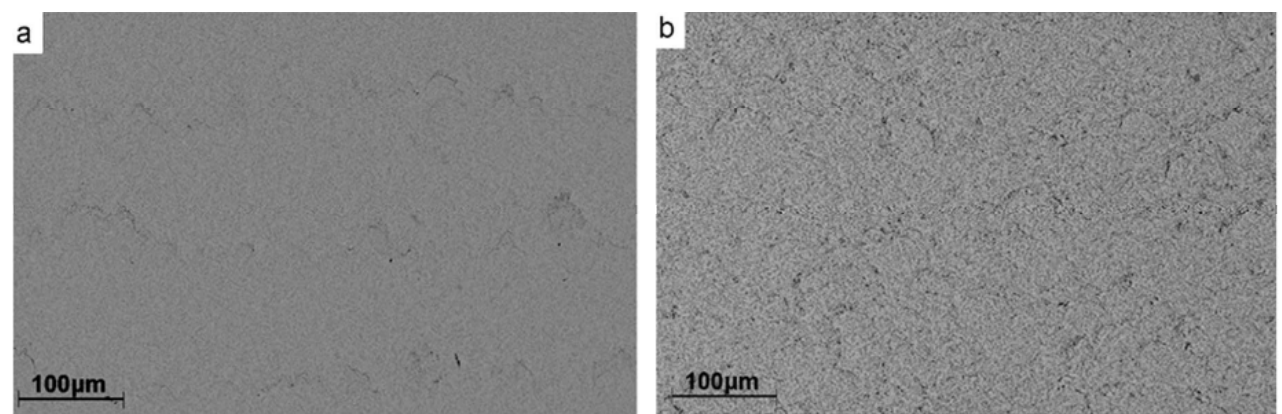

$155 \times 50 \mathrm{~mm}(300 \times 300 \mathrm{DPI})$ 


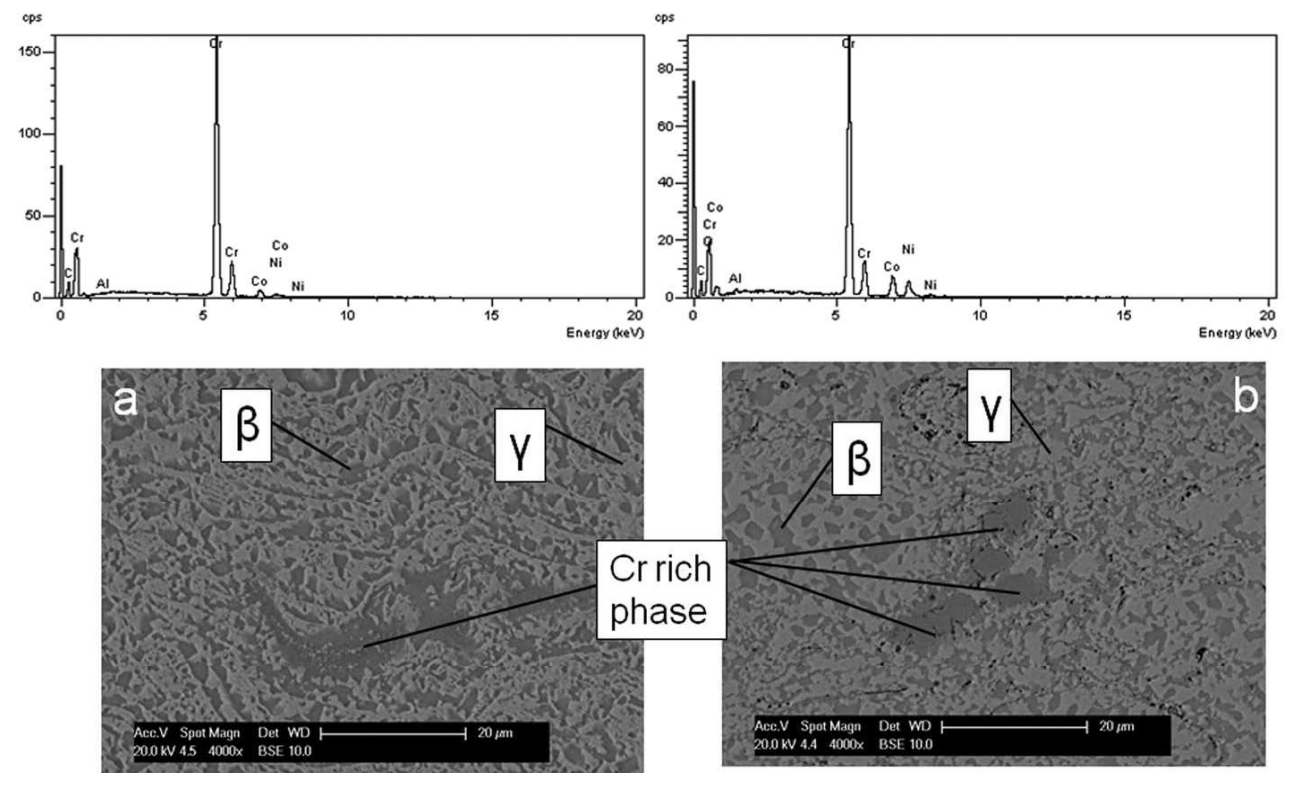

$119 \times 71 \mathrm{~mm}(300 \times 300 \mathrm{DPI})$ 


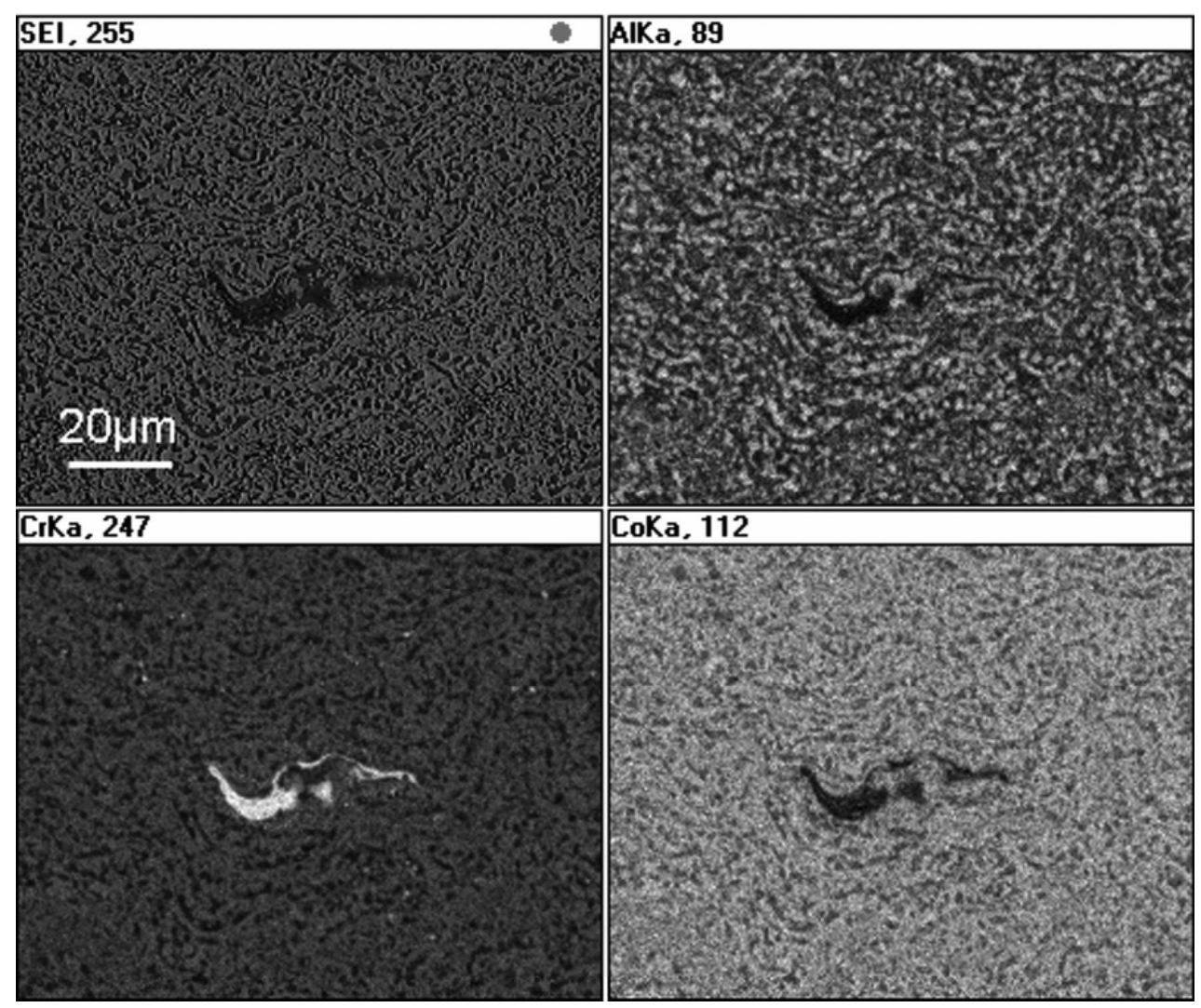

$150 \times 126 \mathrm{~mm}(300 \times 300$ DPI $)$ 


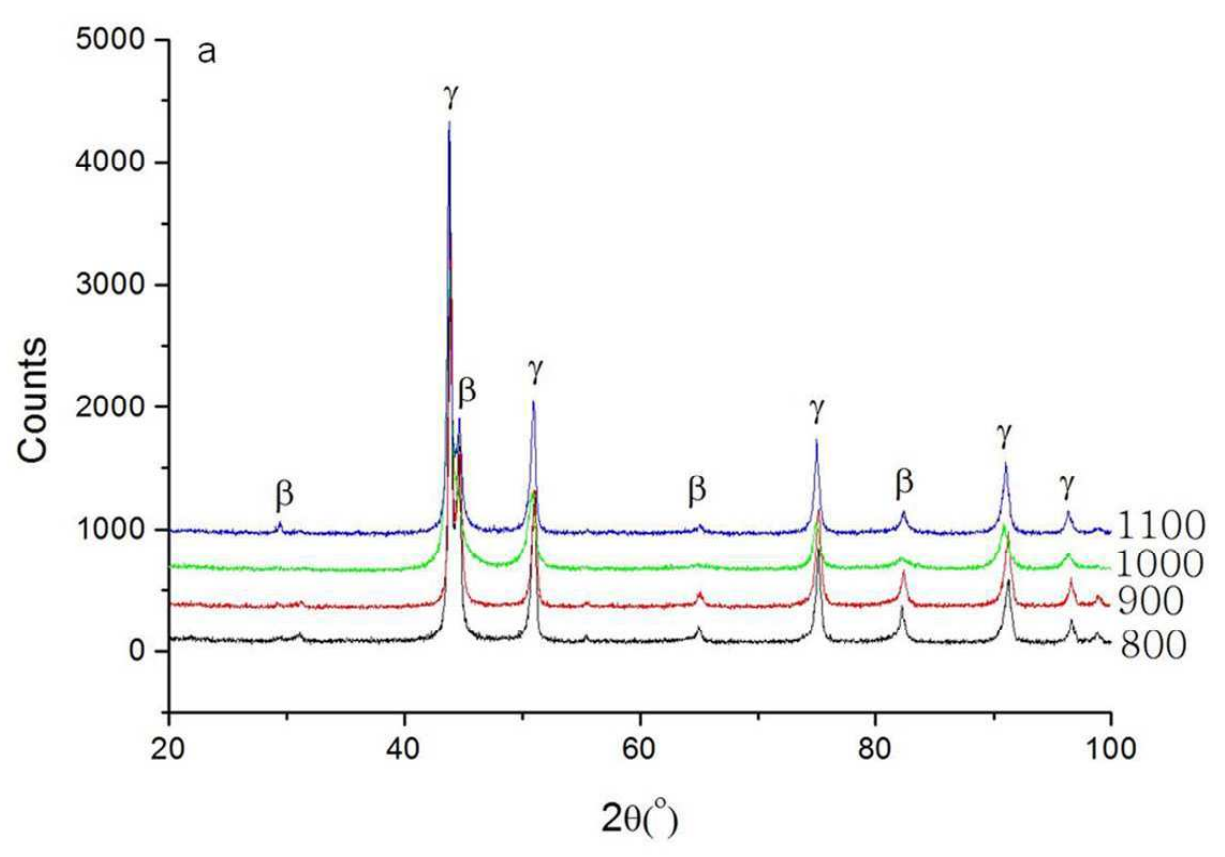

$99 \times 75 \mathrm{~mm}(300 \times 300 \mathrm{DPI})$ 


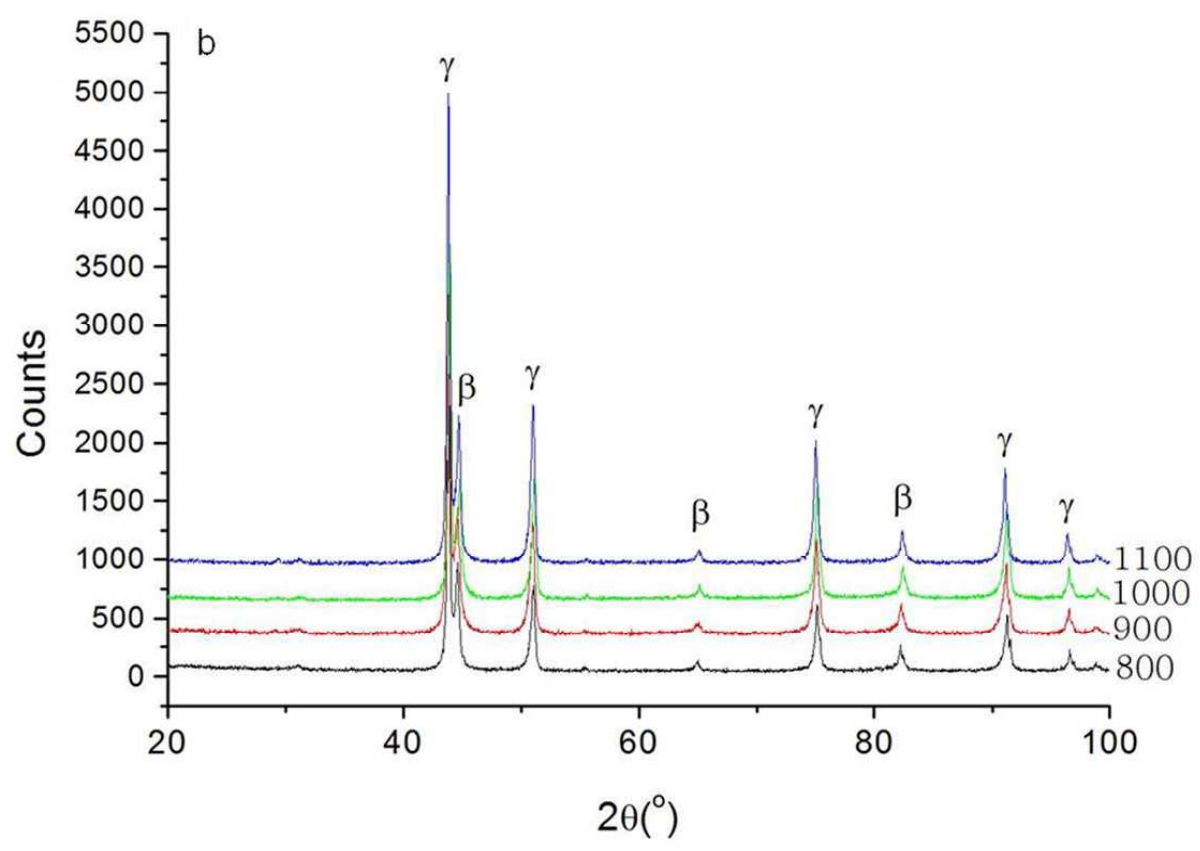

$99 \times 75 \mathrm{~mm}(300 \times 300 \mathrm{DPI})$ 


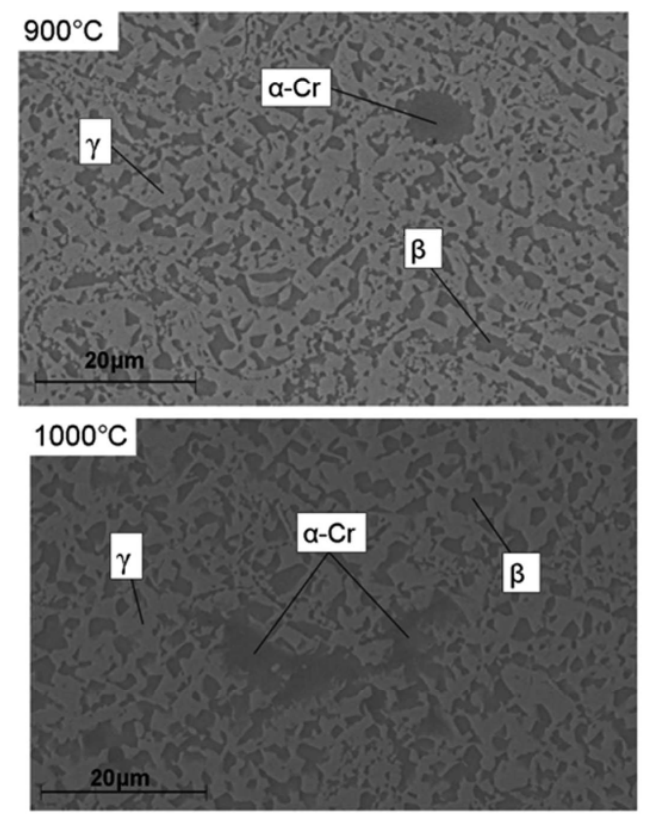

(a)
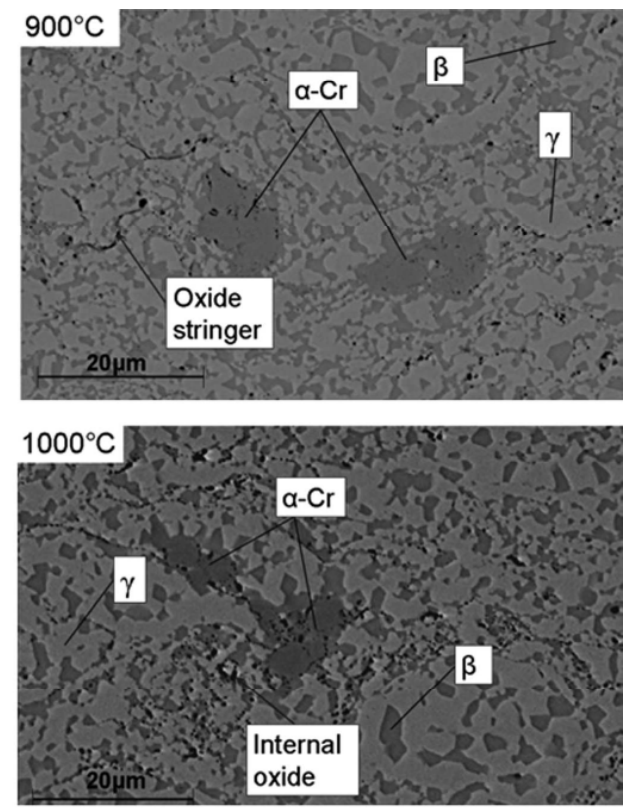

(b)

$180 \times 129 \mathrm{~mm}(300 \times 300$ DPI $)$ 

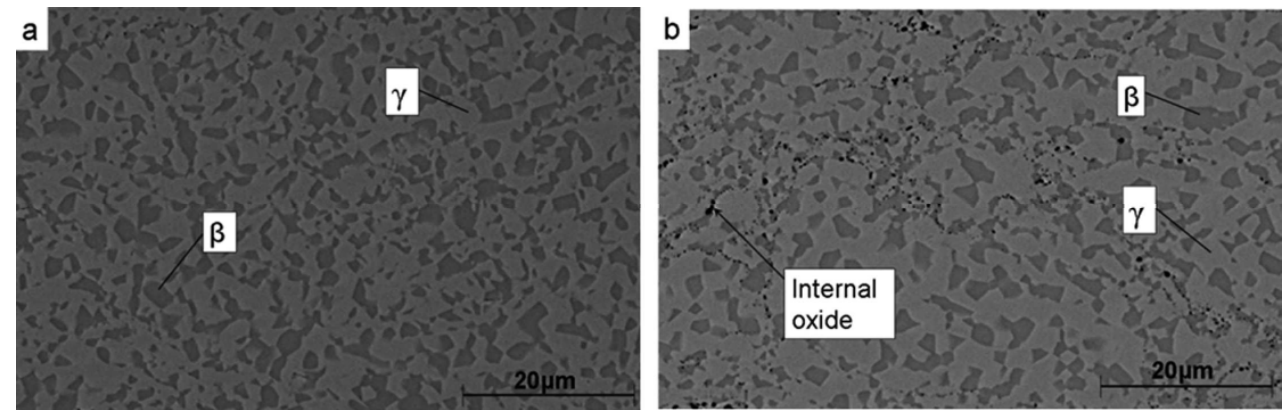

$188 \times 60 \mathrm{~mm}(300 \times 300 \mathrm{DPI})$ 


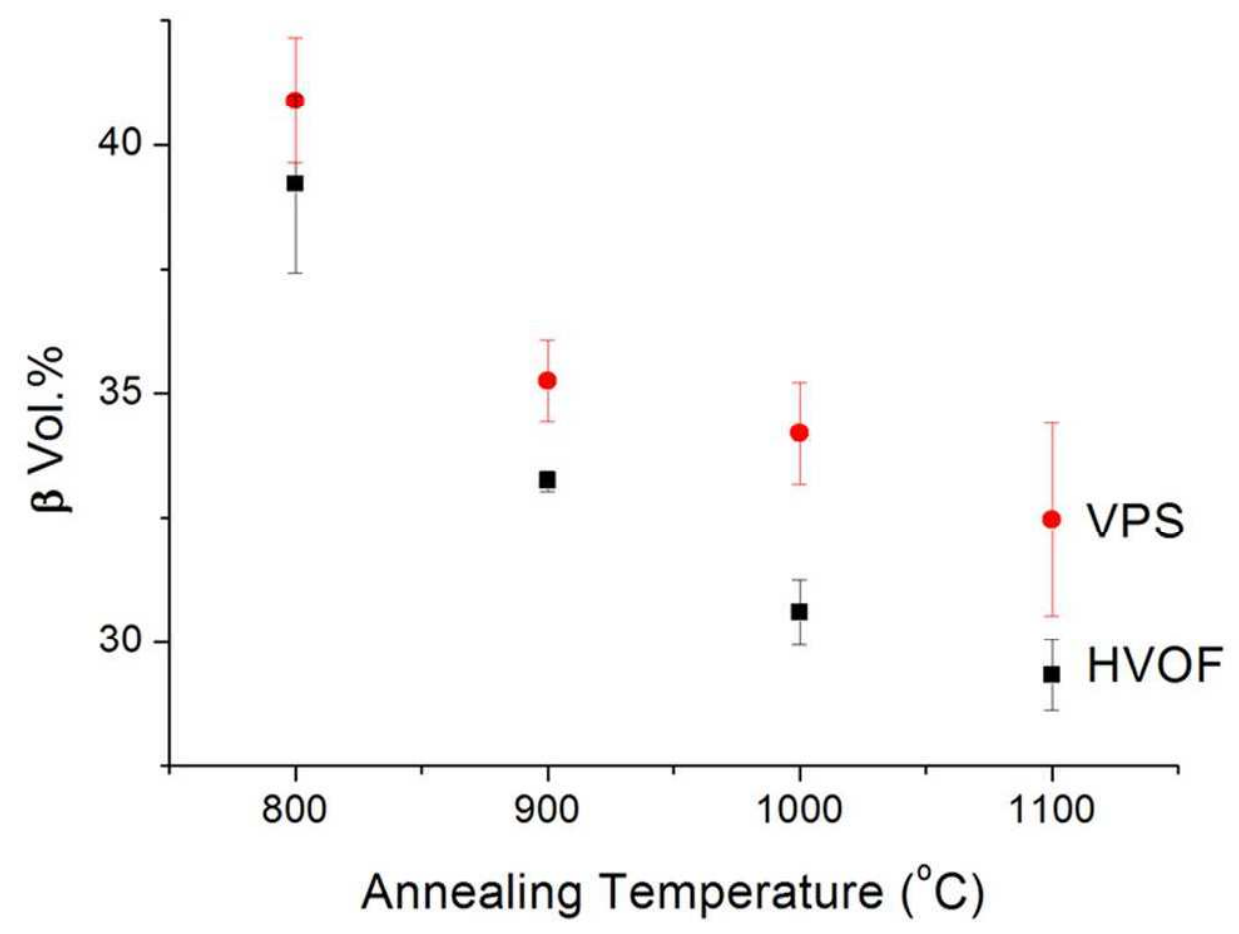

$85 \times 62 \mathrm{~mm}(300 \times 300 \mathrm{DPI})$ 


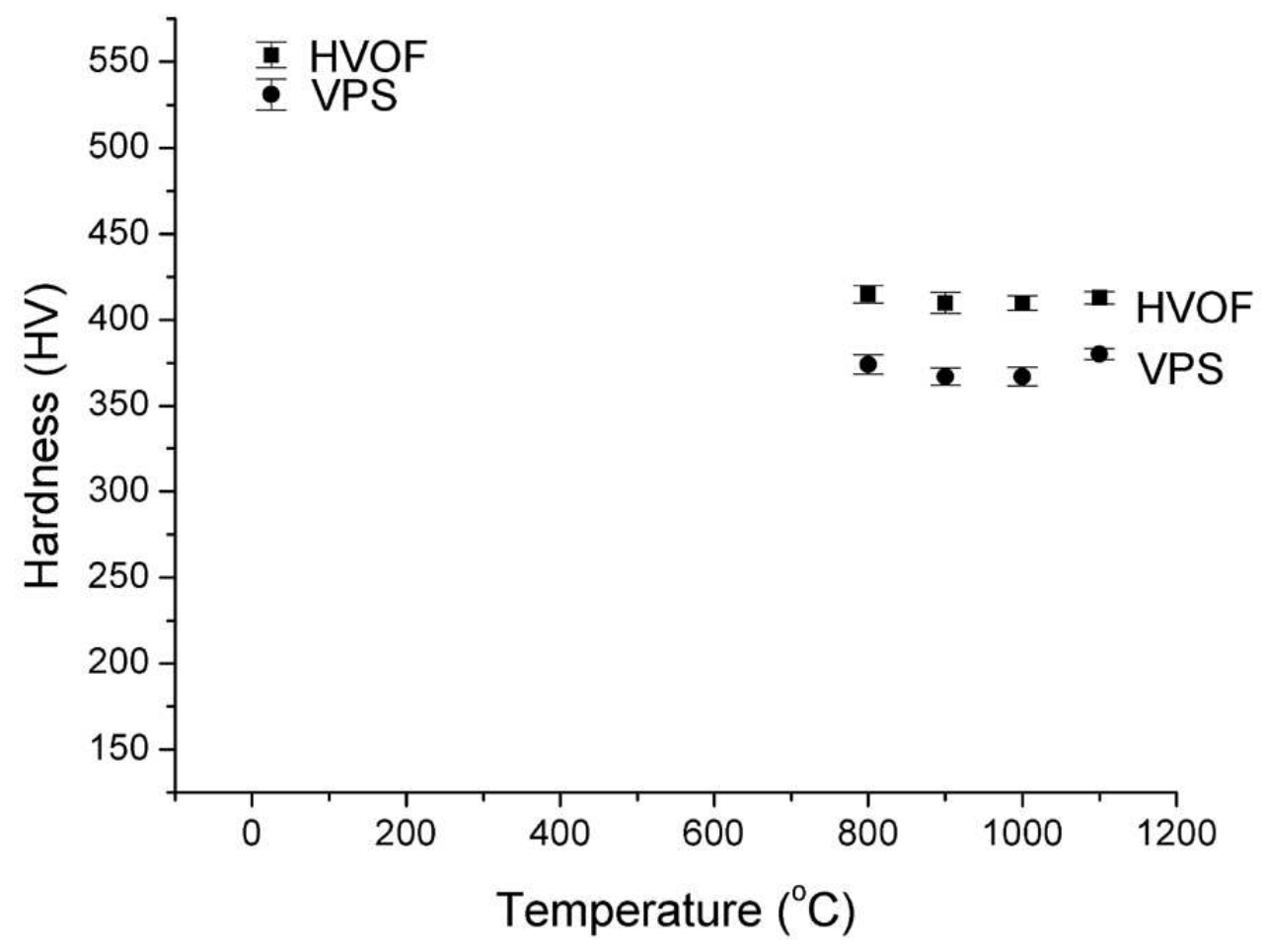

$76 \times 56 \mathrm{~mm}(300 \times 300$ DPI $)$ 


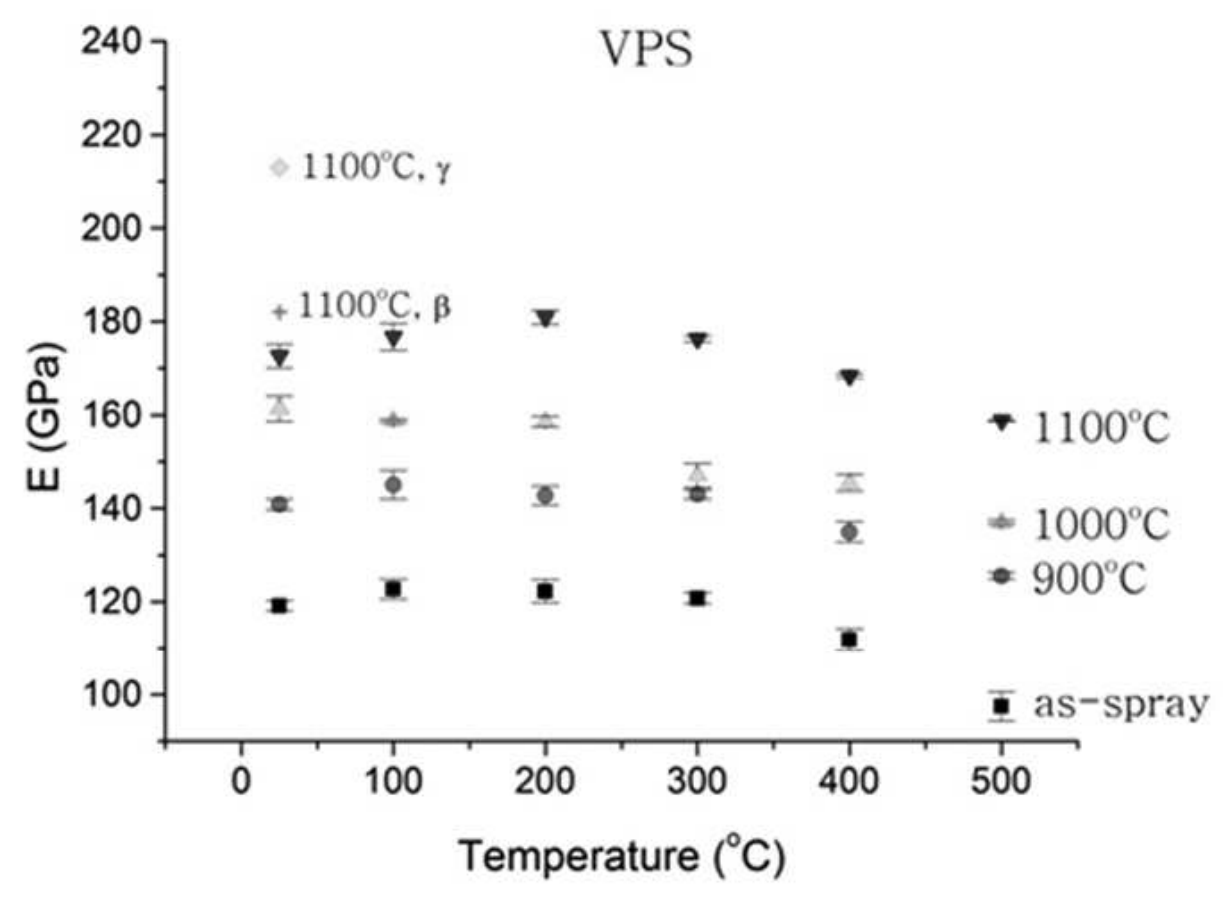

$60 \times 42 \mathrm{~mm}(300 \times 300 \mathrm{DPI})$ 


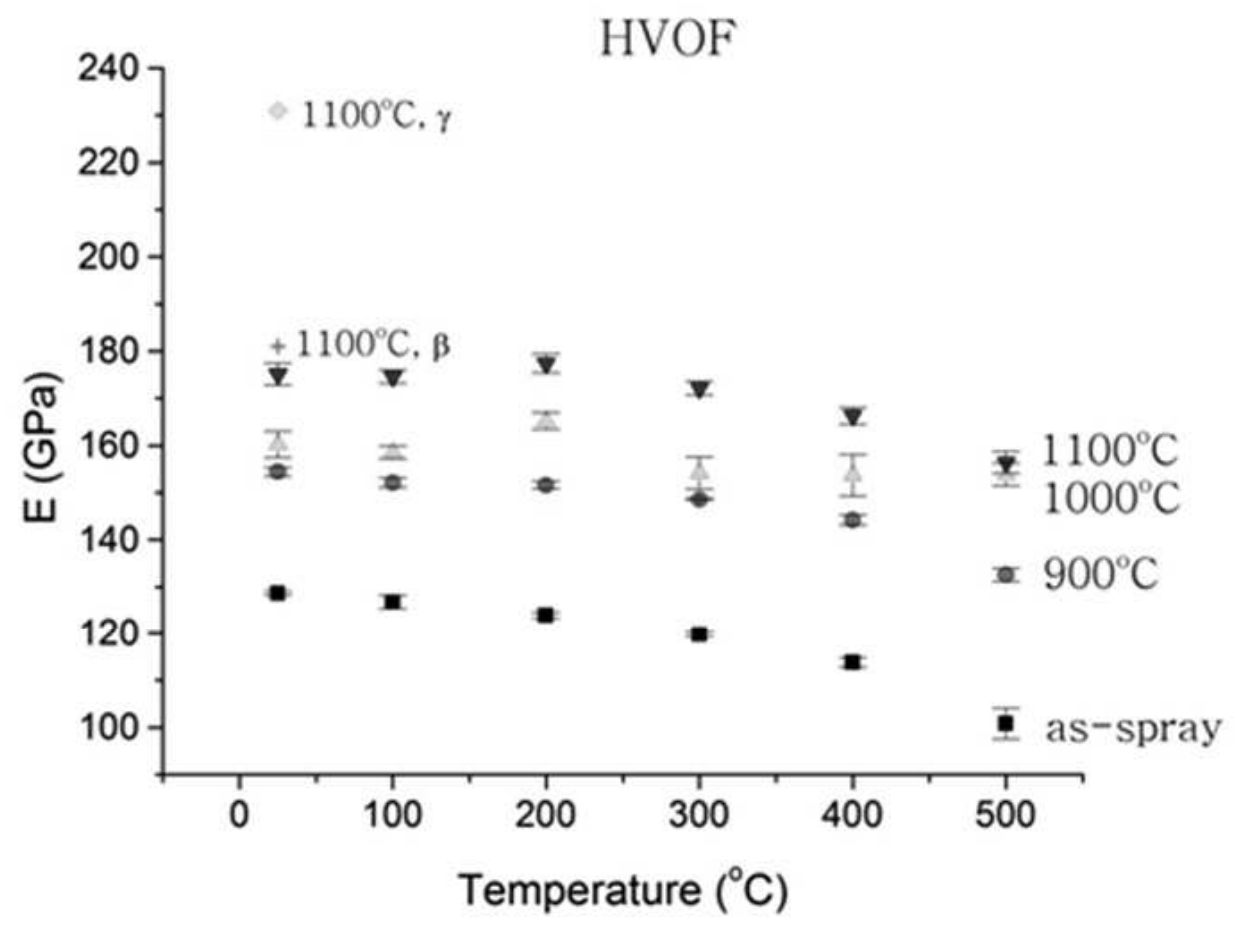

$60 \times 46 \mathrm{~mm}(300 \times 300 \mathrm{DPI})$ 


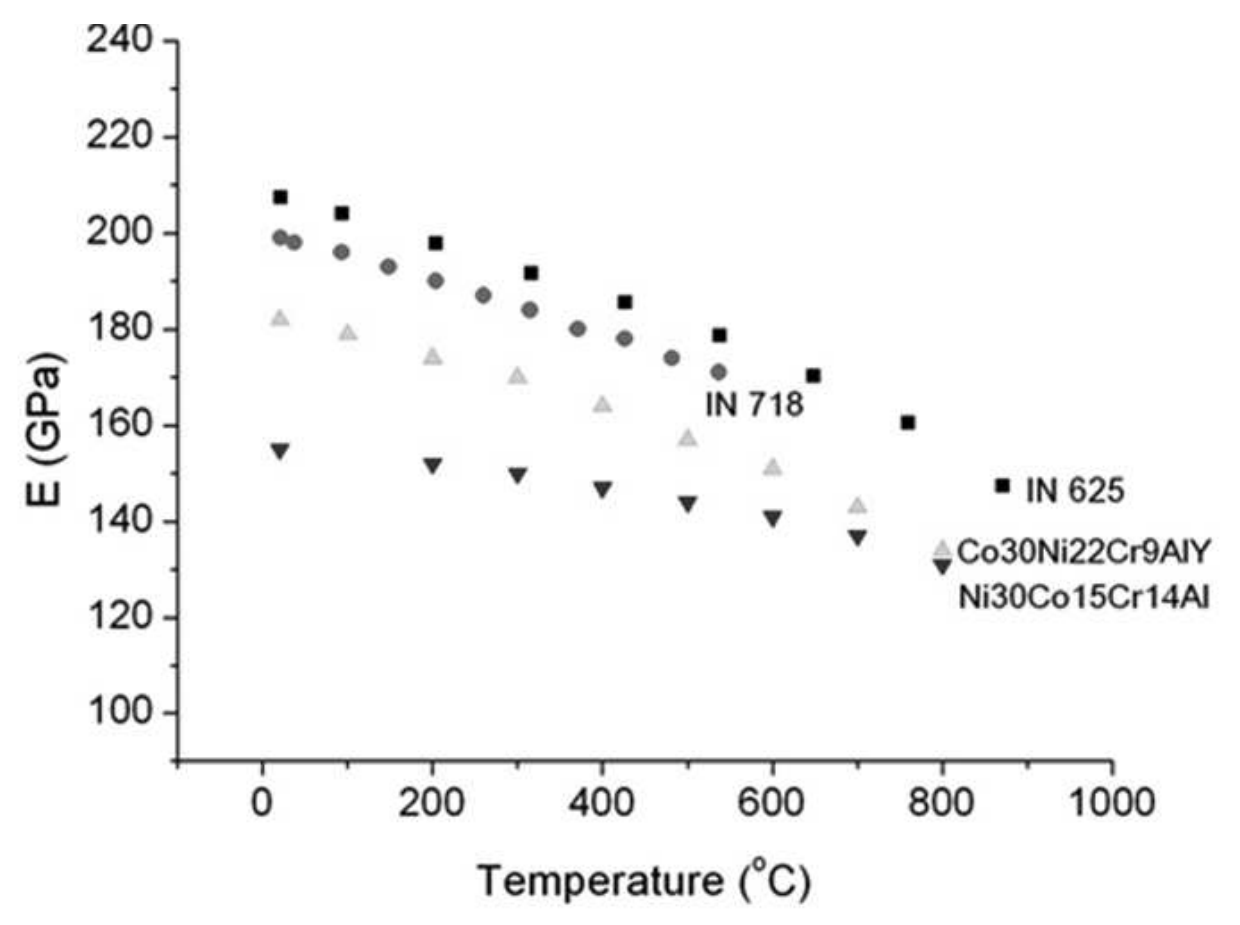

$60 \times 43 \mathrm{~mm}(300 \times 300 \mathrm{DPI})$ 


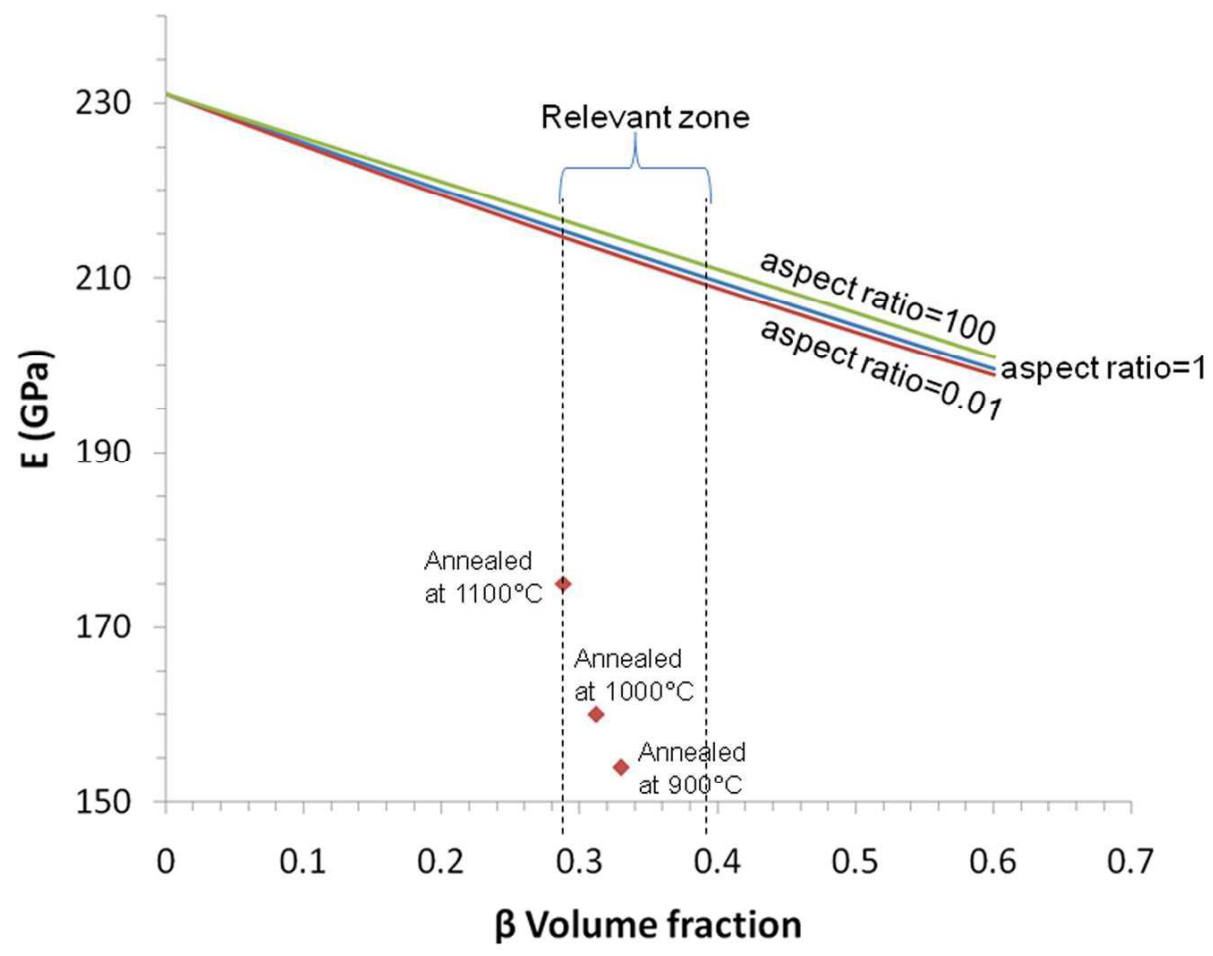

$119 \times 93 \mathrm{~mm}(300 \times 300$ DPI $)$ 

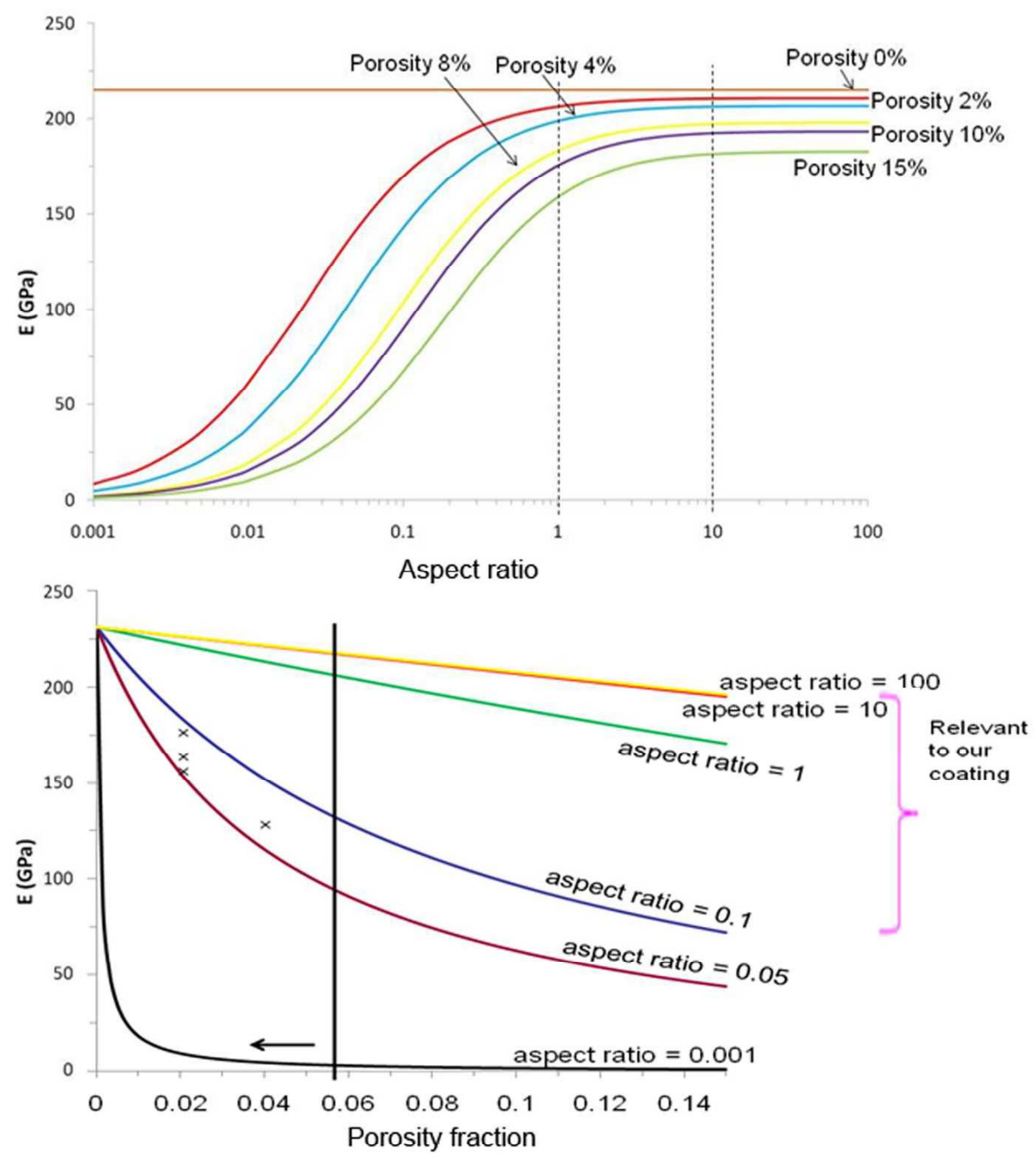

$119 \times 133 \mathrm{~mm}(300 \times 300 \mathrm{DPI})$ 